\title{
Experimental Study of Stress-Seepage Coupling Properties of Sandstone under Different Loading Paths
}

\author{
Xi Chen, ${ }^{1,2}$ Wei Wang $\mathbb{D}^{1,2}$ Yajun Cao, ${ }^{1,2}$ Qizhi Zhu, ${ }^{1,2}$ Weiya $\mathrm{Xu}^{1,2}$ and Huaining Ruan ${ }^{1,2}$ \\ ${ }^{1}$ Geotechnical Research Institute, Hohai University, Nanjing, Jiangsu 210098, China \\ ${ }^{2}$ Key Laboratory of Education for Geomechanics and Embankment Engineering, Hohai University, Nanjing, Jiangsu 210098, China
}

Correspondence should be addressed to Wei Wang; wwang@hhu.edu.cn

Received 12 April 2021; Accepted 15 May 2021; Published 10 June 2021

Academic Editor: Feng Xiong

Copyright ( $92021 \mathrm{Xi}$ Chen et al. This is an open access article distributed under the Creative Commons Attribution License, which permits unrestricted use, distribution, and reproduction in any medium, provided the original work is properly cited.

\begin{abstract}
The study on hydromechanical coupling properties of rocks is of great importance for rock engineering. It is closely related to the stability analysis of structures in rocks under seepage condition. In this study, a series of conventional triaxial tests under drained condition and hydrostatic compression tests under drained or undrained condition on sandstones were conducted. Moreover, complex cyclic loading and unloading tests were also carried out. Based on the experimental results, the following conclusions were obtained. For conventional triaxial tests, the elastic modulus, peak strength, crack initiation stress, and expansion stress increase with increased confining pressure. Pore pressure weakened the effect of the confining pressure under drained condition, which led to a decline in rock mechanical properties. It appeared that cohesion was more sensitive to pore pressure than to the internal friction angle. For complex loading and unloading cyclic tests, in deviatoric stress loading and unloading cycles, elastic modulus increased obviously in first loading stage and increased slowly in next stages. In confining pressure loading and unloading cycles, the Biot coefficient decreased first and then increased, which indicates that damage has a great impact on the Biot coefficient.
\end{abstract}

\section{Introduction}

For underground engineering, geological materials are mostly saturated, and pores and fissures are filled with one or several kinds of fluids. The relation between geological materials and fluids is called the stress-seepage coupling. Stress-seepage coupling is a fundamental problem in rock mechanics, with the characteristics of homogeneity and anisotropy. It is a problem in the construction of water conservancy and hydropower projects $[1,2]$ because internal structures contain defects such as micropores and cracks; those provide a medium for underground water infiltration and flow. Under low stress, rock mass permeability is low, and engineering safety is high; however, the permeability under high stress increases dramatically, which is a serious threat to engineering safety. Rock permeability is related to many factors, and in a large geological structure, permeability in the formation is inconsistent. When rock is in a stressseepage coupling stage, the volumes of inner structure cracks and particles deform under pressure, which has a large influ- ence on rock's penetrability. Also, under the action of a seepage field, seepage hydrostatic and dynamic pore pressures make rock cracks open and connect, which increases the penetration significantly. Also, as time accumulates, weakening by groundwater and chemical corrosion causes significant changes in environment's stress field, which has a large effect on the stability of a geological project. On the other hand, during the construction process, rocks are often under loading and unloading cyclic situations. For example, the excavation of underground water-sealed oil storage is a typical unloading process, and the oil storage process is a typical loading process. Therefore, the study of rock stress-seepage coupling interactions under different loading paths is an important subject in the field of geotechnical engineering, and research on it is of great theoretical and engineering significance.

Scholars worldwide have done much relevant research. Wang et al. [3] used a rock mechanics test system on sandstone as well as limestone in order to conduct triaxial compression tests, the results showed the permeability 


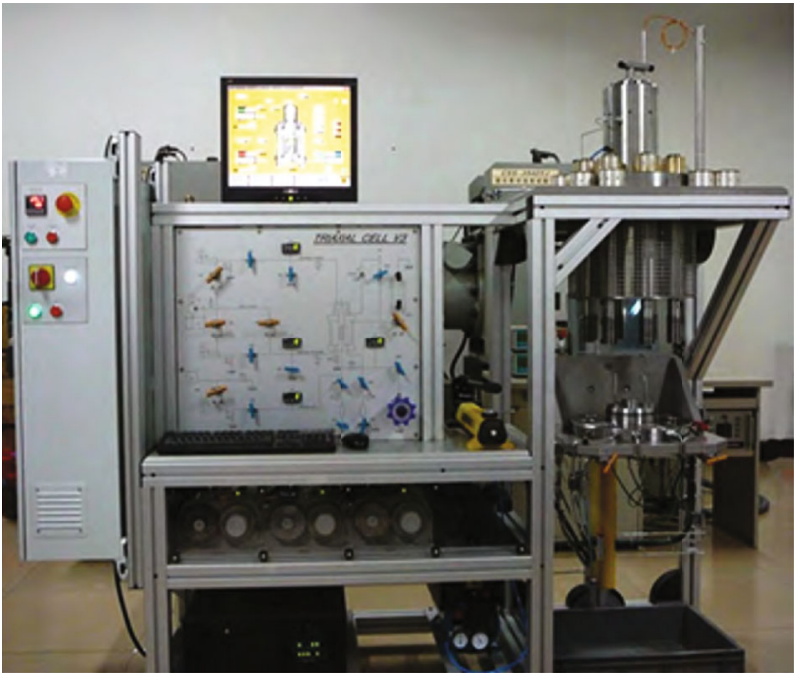

FiguRE 1: Rock servo-controlled triaxial system.

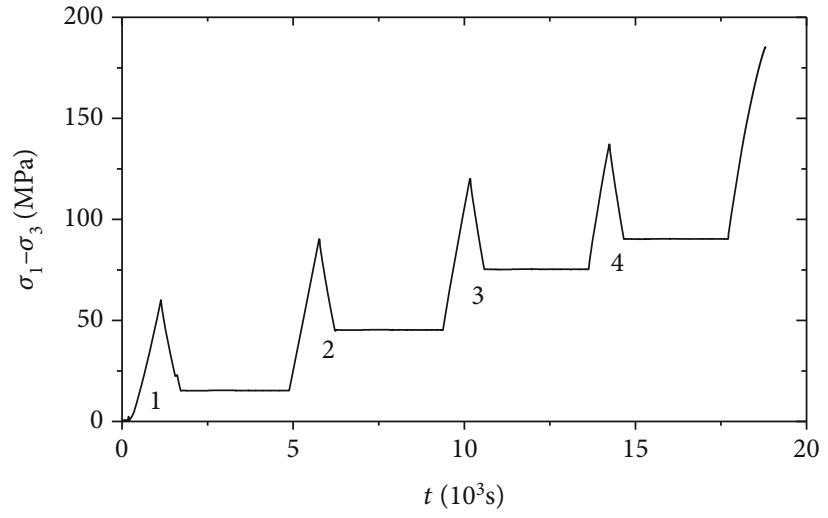

(a)

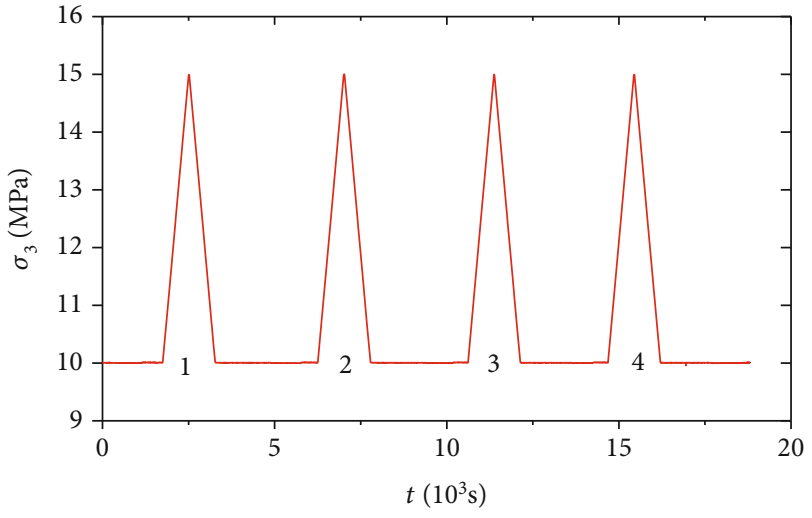

(b)

FIGURE 2: The deviatoric stress and confining pressure loading path. (a) The deviatoric stress loading path. (b) The confining pressure loading path.

evolutionary characteristics during rock failure and the relationship between rock strength, deformation, and permeability before and after failure. Wang et al. [4] did permeable experiments on complete stress-strain courses of limestone and sandstone in a servo-controlled testing machine. The results showed that the permeability of a rock specimen was closely related to its stress state, and the peak value of permeability coincided with the peak value of stress-strain, which was closely related to the properties of the rock material. Heiland [5] used sandstone to study the permeability evolution during failure process. Wei et al. [6] did stress-seepage coupling tests on granite gneiss to study the difference of rock permeability evolution rules under conventional triaxial compression and axial compression loading and unloading cycles. Zhang et al. [7] used the rock top multifield coupling tester to do seepage tests under hydrostatic pressure conditions and triaxial compression conditions and the mechanical properties and seepage characteristics of red sandstone under different high temperature environments. By using the automatic triaxial seepage experiment system, Zhang et al. [8] carried out a series of stress-seepage coupling tests of sandstone under anhydrous and drainage conditions, and the evolution law of deformation, strength, and permeability of sandstone was investigated under stressseepage coupling condition. The influence of seepage pressure on rock stress-flow coupling characteristics was determined by Yin et al. [9] by using a true triaxial rock test system of coupled stress-seepage. On the basis of the characteristics of loose organizational structure, high moisture content, and poor physical and mechanical properties, Zhang et al. [10] did permeability measurements during time-dependent deformation under hydromechanical coupling and the influence of axial, hoop, and volumetric deformation. They thereby determined the permeability coefficient and the influence of confining pressure and pore pressure on permeability characteristics. To understand the relation between rock permeability and deformation under hydromechanical coupling, a servo-controlled triaxial rock mechanics test system was used by $\mathrm{Yu}$ et al. [11] to investigate the steady-state permeability of sandstone under various confining stresses and osmotic pressures. That study also analyzed the characteristics of the 

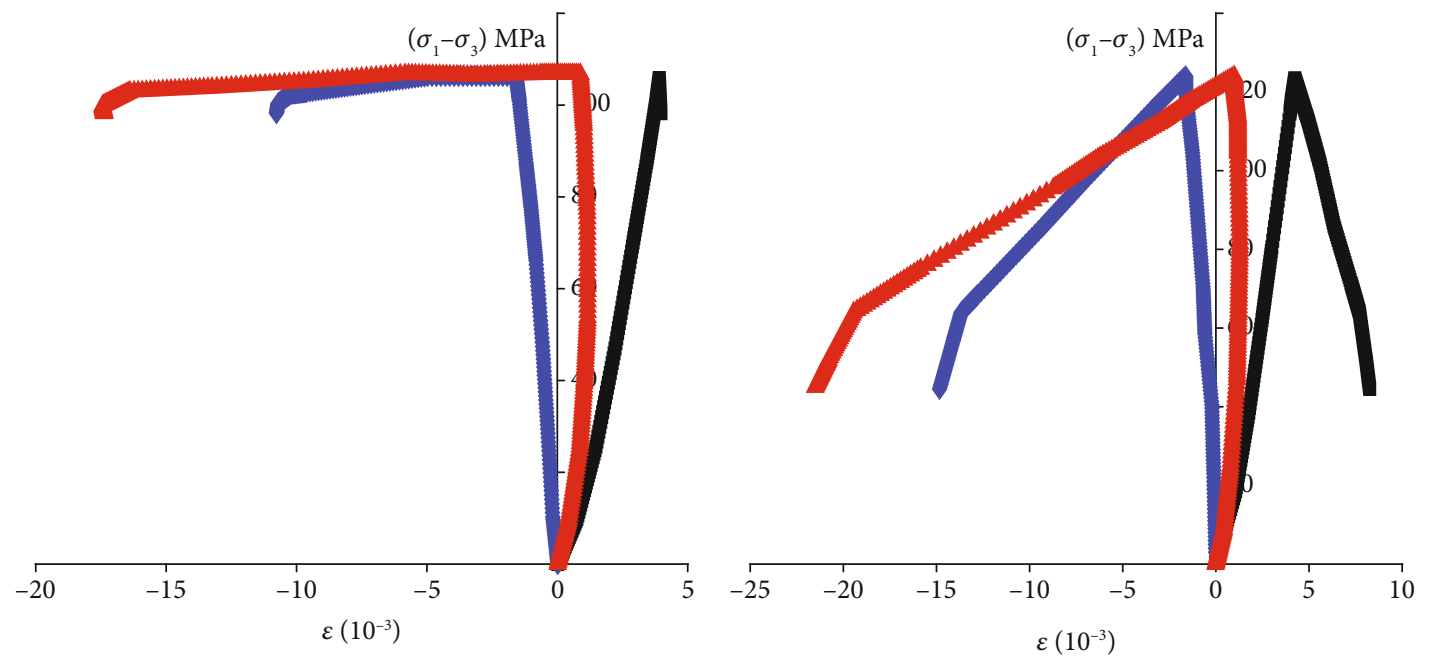

- Axial strain

$\rightarrow-$ Axial strain

$\rightarrow$ Circumferential strain

$\neg-$ Circumferential strain

- Volume strain

(a)
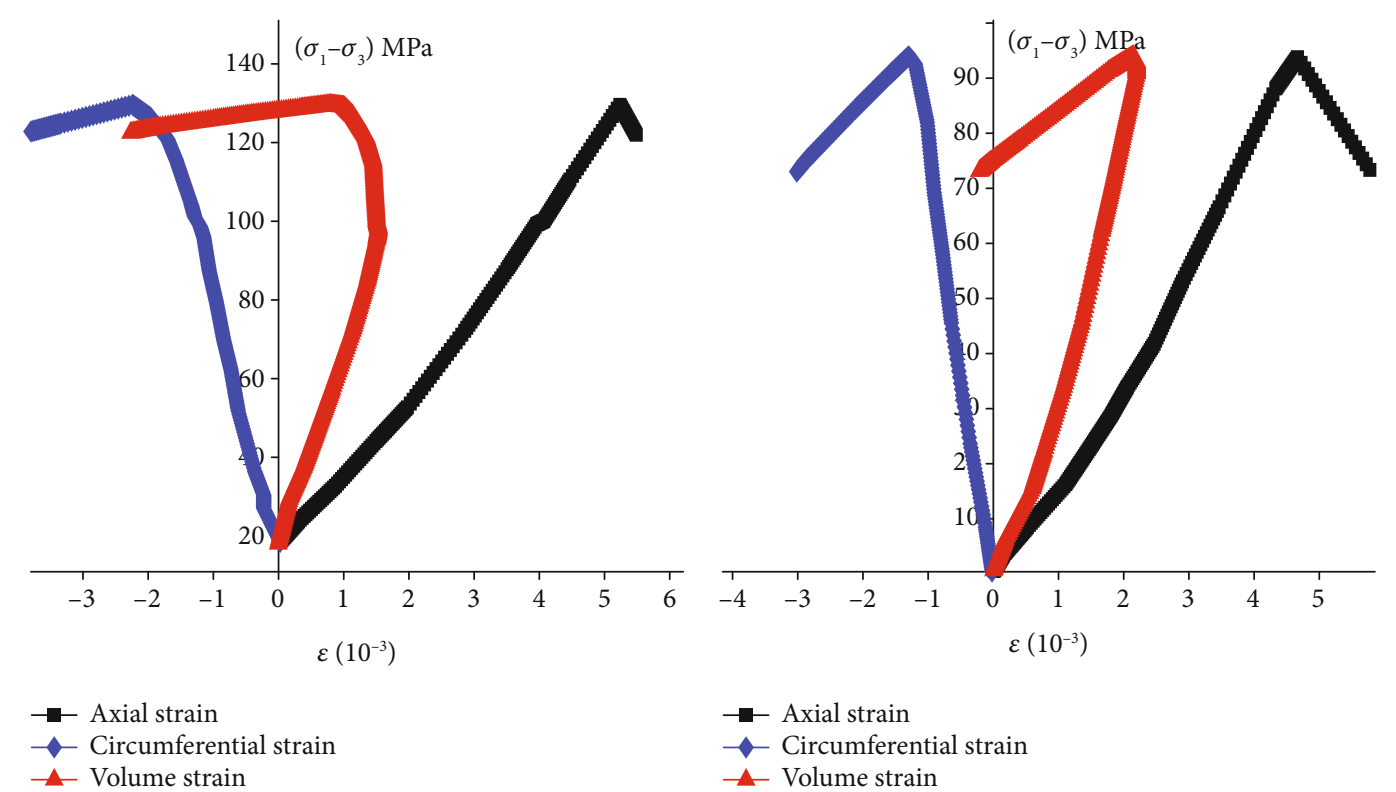

$\rightarrow$ Axial strain

$\neg$ - Circumferential strain

- Volume strain

(d)

(c)

(b) 

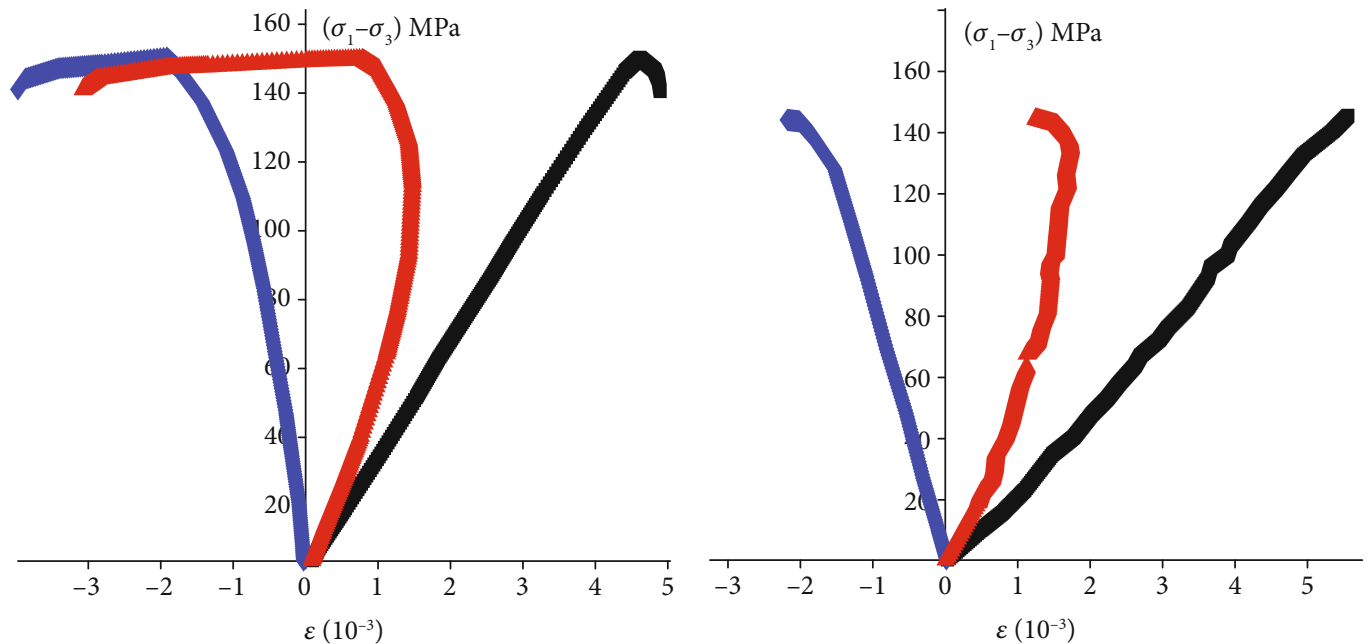

- Axial strain

$\neg$ - Circumferential strain

- Axial strain

$\_$- Volume strain

- Circumferential strain

$\_$Volume strain

(e)

(f)
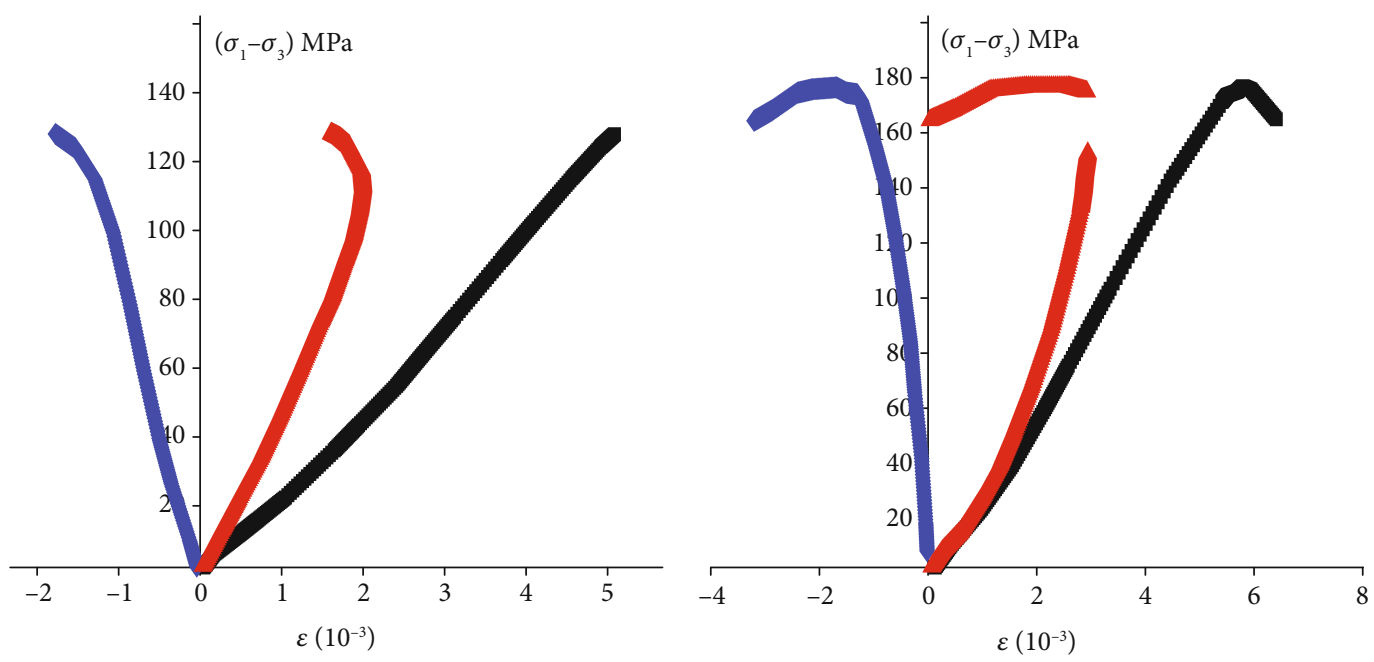

-axial strain

- Axial strain

$\rightarrow$ Circumferential strain

_ Volume strain

$\_$- Volume strain

(g)

(h)

FIgURe 3: Continued. 


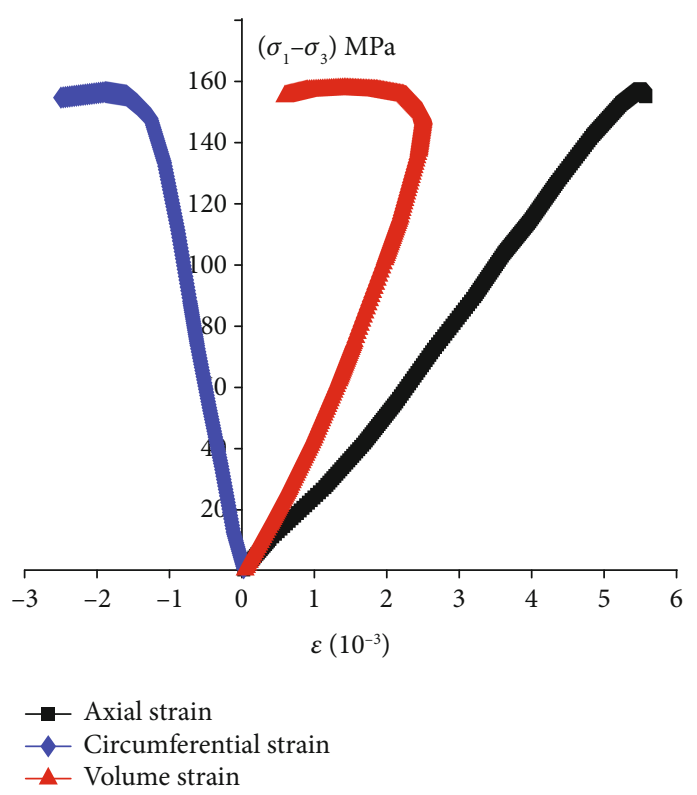

(i)

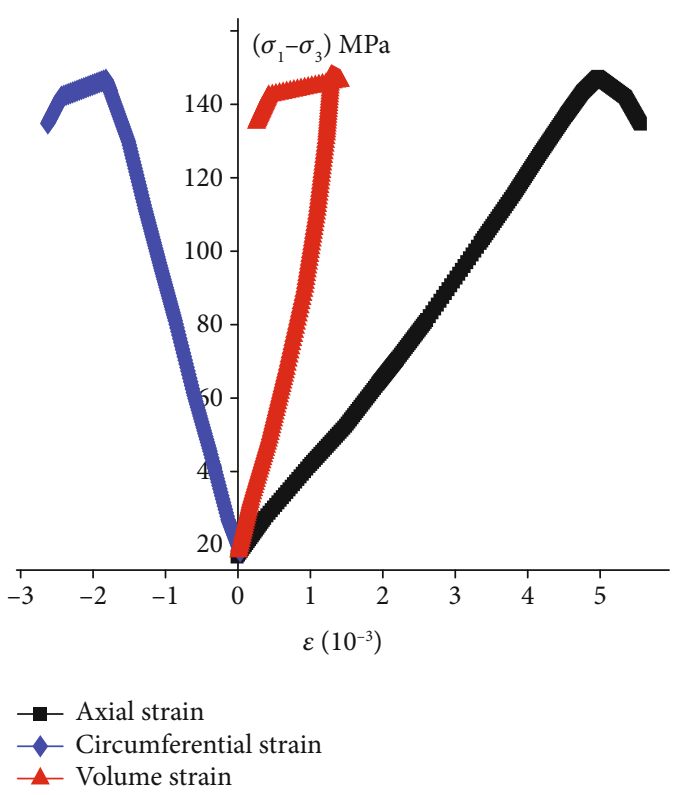

(j)

Figure 3: Relation curves of deviatoric stress with axial, circumferential, and volume strains. (a) $\sigma_{3}=0 \mathrm{MPa}, p=0 \mathrm{MPa}$. (b) $\sigma_{3}=5 \mathrm{MPa}, p$ $=0 \mathrm{MPa}$. (c) $\sigma_{3}=5 \mathrm{MPa}, p=1 \mathrm{MPa}$. (d) $\sigma_{3}=5 \mathrm{MPa}, p=3 \mathrm{MPa}$. (e) $\sigma_{3}=10 \mathrm{MPa}, p=0 \mathrm{MPa}$. (f) $\sigma_{3}=10 \mathrm{MPa}, p=1 \mathrm{MPa}$. (g) $\sigma_{3}=10 \mathrm{MPa}$, $p=3 \mathrm{MPa}$. (h) $\sigma_{3}=15 \mathrm{MPa}, p=0 \mathrm{MPa}$. (i) $\sigma_{3}=15 \mathrm{MPa}, p=1 \mathrm{MPa}$. (j) $\sigma_{3}=15 \mathrm{MPa}, p=3 \mathrm{MPa}$.

TABLE 1: Mechanical parameters of a natural sandstone sample under different pore pressures.

\begin{tabular}{lcc}
\hline Pore pressure $(\mathrm{MPa})$ & $c^{1}(\mathrm{MPa})$ & $\varphi^{2}\left(^{\circ}\right)$ \\
\hline 0 & 24.09 & 40.40 \\
1 & 32.74 & 29.79 \\
\hline
\end{tabular}

${ }^{1}$ Cohesive strength. ${ }^{2}$ The angle of internal friction.

permeability of samples, their brittleness and ductility during the stress and strain process, and the correlation between permeability-axial strain and permeabilityvolumetric strain. The research of Yin and Chen [12] concerned the influences of seepage pressure on joint stressseepage coupling characteristics, changing trends of rock stress, displacement, joint hydraulic apertures, and conductivity along with shear displacement. Their results indicated that shear stress, displacement, hydraulic apertures, and conductivity of joint specimens were distinctly related to seepage. On the other hand, Oda et al. and Schulze et al. $[13,14]$ conducted some relevant research on permeability evolution under triaxial compression which showed that rock deformation damage had a large effect on permeability characteristics, and we could obtain the conclusion that there is currently an understanding of stressstrain characteristics under seepage pressure. Lu et al. [15] found that with pore pressure through triaxial compression tests in an undrained condition, the deviatoric stress curve had a parabola trend, which meant that the failure process would appear at the peak stress point, the rock internal microcrack openings joined, and the pore pressure decreased rapidly. Sun et al. [16] used a stressseepage coupling true triaxial test system to do a coupling test of stress and seepage to establish a single-fracture triaxial stress-seepage coupling model with large-scale rock specimens. They also obtained a fitting formula for the permeability coefficient.

In actual underground engineering, rock materials are in a complex stress environment, and the stress state of underground rock materials is extremely complex, and most of them are the combined effect of multiple stress factors such as deviatoric stress, hydrostatic pressure, and pore pressure. Therefore, many scholars used the cyclic loading and unloading tests to simulate the complex stress of rock engineering during construction process. It is also found that both the peak and residual stress and the failure strain are well correlated with humidity level for Cox claystone by a series tests and modeling research on water saturated degree as well as relative humidity effect $[6,17-$ 24]. The results give the implications that the desaturation and resaturation would exert influences on its surroundings in the underground repositories. Hu et al. [25] studied the anisotropic mechanical behavior, the Biot coefficient, and permeability coefficient caused by the development of microcrack tendency through complex cyclic loading and unloading tests on brittle rocks. Su et al. [26] obtained the conclusion that during the triaxial cyclic loading and unloading test, the deformation of coal sample showed obvious memory characters, and the elastic modulus increased slightly with the increase of the cyclic series. Zuo et al. [27] conducted a loading and unloading test on coal-rock combination and believed that during the loading and unloading cycle, the loading elastic modulus increased rapidly at first, then slowly increased, and then gradually decreased after reaching the maximum value. The unloading elastic modulus had a small change, 
TABLE 2: Mechanical parameters of drained sandstone obtained from triaxial compression test.

\begin{tabular}{lccccccccc}
\hline Sample number & $\begin{array}{c}\sigma_{3}{ }^{1} \\
(\mathrm{MPa})\end{array}$ & $\begin{array}{c}P^{2} \\
(\mathrm{MPa})\end{array}$ & $\begin{array}{c}\sigma_{\mathrm{c}}{ }^{3} \\
(\mathrm{MPa})\end{array}$ & $\begin{array}{c}\sigma_{\mathrm{ci}}{ }^{4} \\
(\mathrm{MPa})\end{array}$ & $\begin{array}{c}\sigma_{\mathrm{cd}}{ }^{5} \\
(\mathrm{MPa})\end{array}$ & $\begin{array}{c}\sigma_{\mathrm{cc}}{ }^{6} \\
(\mathrm{MPa})\end{array}$ & $\begin{array}{c}E^{7} \\
\mathrm{GPa}\end{array}$ & $\begin{array}{c}\mu^{8} \\
\sigma_{\mathrm{ci}}: \sigma_{\mathrm{c}}\end{array}$ \\
\hline SY-1 & 0 & 0 & 106.88 & 65.77 & 72.31 & 23.27 & 32.92 & 0.486 \\
SY-2 & 5 & 0 & 123.89 & 58.83 & 90.48 & 25.31 & 33.33 & 0.394 & 0.615 \\
SY-3 & 5 & 1 & 126.53 & 71.57 & 98.81 & 35.93 & 25.99 & 0.286 & 0.566 \\
SY-4 & 5 & 3 & 93.60 & 53.27 & 88.73 & 23.07 & 23.15 & 0.263 & 0.569 \\
SY-5 & 10 & 0 & 150.68 & 80.91 & 119.36 & 30.35 & 34.01 & 0.328 & 0.537 \\
SY-6 & 10 & 1 & 145.10 & 73.45 & 131.57 & 27.56 & 27.96 & 0.292 & 0.506 \\
SY-7 & 10 & 3 & 128.04 & 60.26 & 111.22 & 30.40 & 27.58 & 0.295 \\
SY-8 & 15 & 0 & 175.95 & 95.90 & 165.56 & 38.03 & 35.21 & 0.278 \\
SY-9 & 15 & 1 & 156.26 & 78.57 & 137.38 & 43.80 & 31.97 & 0.246 \\
SY-10 & 15 & 3 & 146.08 & 74.45 & 144.86 & 58.17 & 31.53 & 0.53 \\
\hline
\end{tabular}

${ }^{1}$ Confining pressure, ${ }^{2}$ pore pressure, ${ }^{3}$ peak strength, ${ }^{4}$ crack initiation stress, ${ }^{5}$ expansion stress, ${ }^{6}$ crack closure stress, ${ }^{7}$ elastic modulus, ${ }^{8}$ Poisson's ratio.

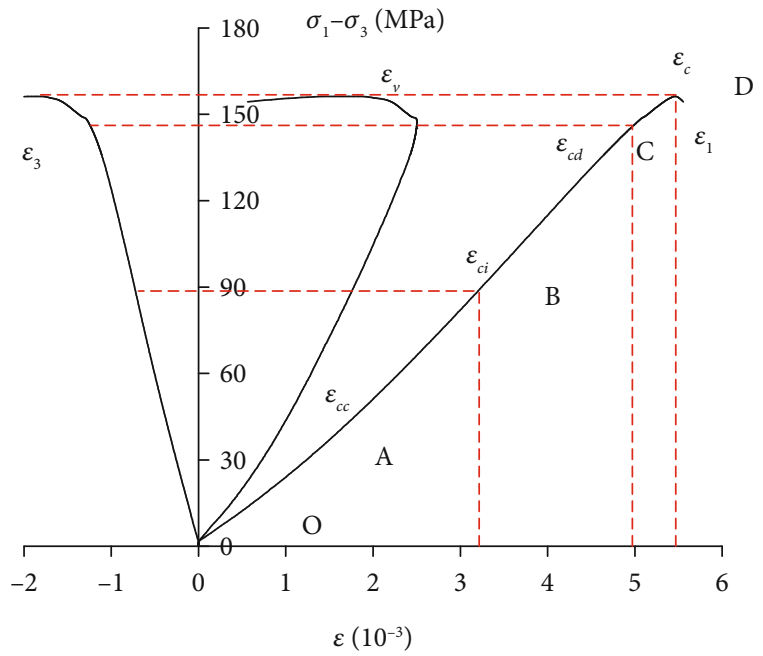

FIgURE 4: Progressive failure process of triaxial compression test.

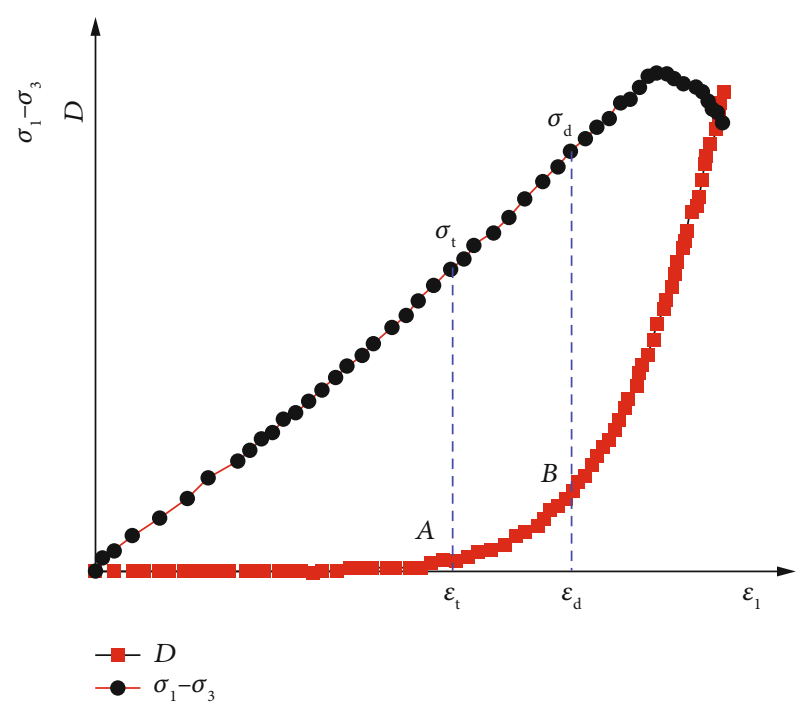

FIGURE 5: Evolution of axial strain and damage variables under triaxial compression. and it also experienced a process of slowly increasing first and then slowly decreasing.

In summary, the existing test results mostly reflected the relation between permeability, stress, strain, and pore pressure on different drainage conditions, but few studies have been done on stress-seepage coupling tests on systematic complex loading and unloading cyclic condition with considering the extent of damage. Therefore, on the basis of previous studies, this study took sandstone as the research object and examined rock strength characteristics, deformation laws, and damage caused by confining pressure and pore pressure through triaxial compression tests under various confining pressures and pore pressures. Moreover, complex cyclic loading and unloading tests and hydrostatic pressure tests were also carried out to do research on deformation and damage evolution on sandstone.

\section{Experimental Preparations}

2.1. Material Characterization and Sample Preparation. The instrument used in this study was a rock servocontrolled triaxial system (Figure 1), in which the model of this system that has been proven to have a good performance in rock triaxial compressive testing [28] is derived from Lamcube laboratory (Laboratoire de M'ecanique, Multiphysique, Multi'echelle) of the University of Lille. The system consists of four independent components [29]. The three components for axial stress loading, confining pressure application, and interstitial pressure generation are assembled around the triaxial cell, and the fourth component is assured by a regulated oven located in a room for which the temperature is regulated at $20 \pm 0.5^{\circ}$ C. The sandstone used in these tests was cored from the high slope on the left bank of Jinping I Hydropower Station, which comprised mainly quartz, feldspar, and calcite that had no significant cracks. The rock surface is grayish white, without obvious cracks, with a natural density of $2.70 \mathrm{~g} / \mathrm{cm}^{3}$. The sandstone was drilled into standard cylindrical samples $50 \mathrm{~mm}$ in diameter and $100 \mathrm{~mm}$ long; they were numbered from SY-1 to SY-13. 
TABLE 3: Characteristic parameters under various stress states.

\begin{tabular}{|c|c|c|c|c|c|c|c|c|}
\hline Sample number & $\begin{array}{c}\sigma_{3} \\
\mathrm{MPa}\end{array}$ & $\begin{array}{c}P \\
\mathrm{MPa}\end{array}$ & $m$ & $\varepsilon 0^{1} / 10^{-3}$ & $\begin{array}{c}\sigma_{\mathrm{t}}^{2} \\
\mathrm{MPa}\end{array}$ & $\sigma_{\mathrm{t}}: \sigma_{\mathrm{c}}$ & $\begin{array}{c}\sigma_{\mathrm{d}}^{3} \\
\mathrm{MPa}\end{array}$ & $\sigma_{\mathrm{d}}: \sigma_{\mathrm{c}}$ \\
\hline SY-1 & 0 & 0 & 5.441 & 5.494 & 40.85 & 0.382 & 89.50 & 0.837 \\
\hline SY-2 & 5 & 0 & 5.393 & 5.921 & 47.77 & 0.386 & 102.40 & 0.827 \\
\hline SY-3 & 5 & 1 & 6.902 & 6.982 & 65.90 & 0.521 & 106.70 & 0.843 \\
\hline SY-4 & 5 & 3 & 6.126 & 6.411 & 41.70 & 0.446 & 79.80 & 0.853 \\
\hline SY-5 & 10 & 0 & 7.740 & 6.281 & 87.01 & 0.577 & 125.80 & 0.834 \\
\hline SY-6 & 10 & 1 & 6.971 & 7.287 & 77.90 & 0.537 & 129.70 & 0.893 \\
\hline SY-7 & 10 & 3 & 6.712 & 6.826 & 63.13 & 0.493 & 105.10 & 0.820 \\
\hline SY-8 & 15 & 0 & 5.166 & 7.939 & 77.81 & 0.437 & 149.90 & 0.852 \\
\hline SY-9 & 15 & 1 & $6 . .263$ & 7.322 & 75.55 & 0.483 & 131.40 & 0.841 \\
\hline SY-10 & 15 & 3 & 7.026 & 6.577 & 78.50 & 0.537 & 125.40 & 0.858 \\
\hline
\end{tabular}

${ }^{1}$ Initial axial strain, ${ }^{2}$ damage threshold stress, ${ }^{3}$ damaged inflection point stress.

\subsection{Experimental Characterization and Sample Preparation.} Before all the tests, the samples were saturated. Firstly, the rock sample was put into the pumping tank, and the dry pumping was carried out for more than 4 hours by vacuum pump. Then, distilled water was added, and the wet pumping was carried out for more than 8 hours. Finally, the rock sample was soaked for more than 4 hours so that the rock sample was in the saturated state. The laboratory temperature was strictly controlled at $20 \pm 0.5^{\circ} \mathrm{C}$.

For the triaxial compression tests under drained conditions, the confining pressures were 5,10 , and $15 \mathrm{MPa}$, and the pore pressures were 1 and $3 \mathrm{MPa}$. The test methods were as follows:

(1) A saturated sample was put into the apparatus. The load confining pressure and pore pressure were set at predetermined values and kept stable until the water flowed out

(2) Deviatoric stress was applied to the sample. The pore pressure was kept stable. The loading rate was kept at $0.025 \mathrm{~mm} / \mathrm{min}$ until the sample was damaged.

For hydrostatic pressure test and the complex cyclic loading and unloading tests, first, the drained and undrained steps were both concerned to measure the Biot coefficient, and then the deviatoric stress and confining pressure loading and unloading cycles were applied:

(1) Confining pressure was applied to the sample with a low rate as $10^{-2} \mathrm{MPa} / \mathrm{s}$, and pore pressure was kept stable. When confining pressure was loaded to $20 \mathrm{MPa}$, the loading step was stopped and the pressure was unloaded

(2) Confining pressure and pore pressure were both applied to the sample; during the loading step, the confining pressure was first loaded to a set value, and then, pore pressure was loaded to a set value. Then, the two loading rates were kept the same to make hydrostatic pressure increment equal to pore pressure increment. When confining pressure was loaded to $20 \mathrm{MPa}$, the loading step was stopped and the pressure was unloaded

(3) The confining pressure was reloaded to a set value under drained condition with pore pressure as $0 \mathrm{MPa}$ for the whole test. Then, the confining pressure and pore pressure were kept constant, and the deviatoric stress was loaded to a set value, and then the deviatoric stress started the loading-unloading cycle

(4) The deviatoric stress was reloaded to a set value, and then, the deviatoric stress and pore pressure were kept constant, and the confining pressure started the loading-unloading cycle. The loading-unloading steps are shown in Figure 2. The stage level was based on previous triaxial compression tests results.

\section{Results of Triaxial Compression Test of the Drained Samples}

The drained-sample tests were done with samples SY-1 to SY-10, and the stress-strain curve under various confining and pore pressures was determined (Figure 3). The main rock mechanical parameters were determined from the stressstrain curve (Tables 1 and 2).

3.1. Analysis of Rock Strength Characteristics. It was shown in Table 2 that the peak stress $\sigma_{c}$ increased with the confining pressure increased which reflected that the confining pressure could strengthen the rock. In the present study, strength parameters such as internal friction angles and rock cohesion were calculated by test results, as shown in Table 1. It can be seen that the cohesion of the natural sandstone sample was $24.09 \mathrm{MPa}$, and the internal friction angle was $40.40^{\circ}$. Under the same confining pressure, with an increase in pore pressure, the cohesion and internal friction angle changed to a certain extent, especially the cohesion. The cohesion at a pore pressure of $3 \mathrm{MPa}$ reduced by $53.26 \%$ compared to that with a pore pressure 


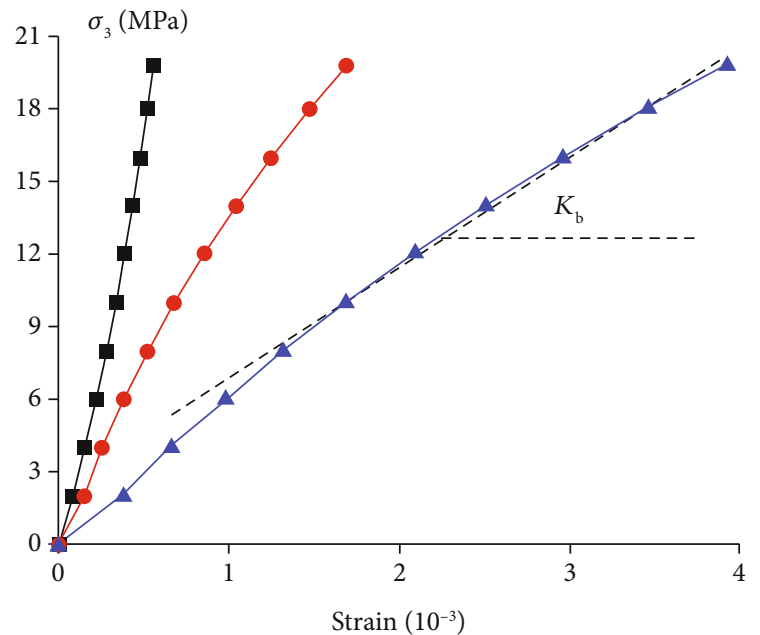

- Axial strain

- Lateral strain

- Volume strain

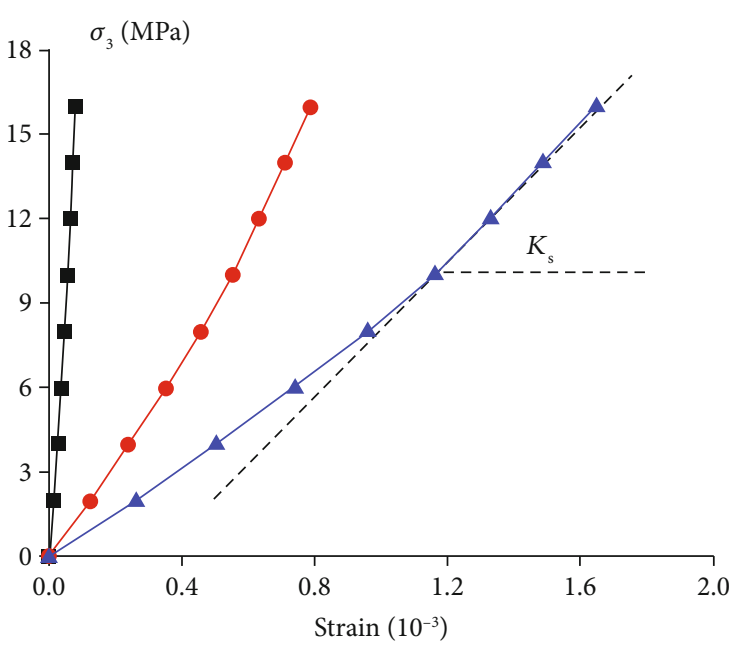

- Axial strain

- Lateral strain

- Volume strain

(a)

(b)

FIGURE 6: Hydrostatic tests results for SY-11. (a) Stress-strain curve under drained condition. (b) Stress-strain curve under undrained condition.

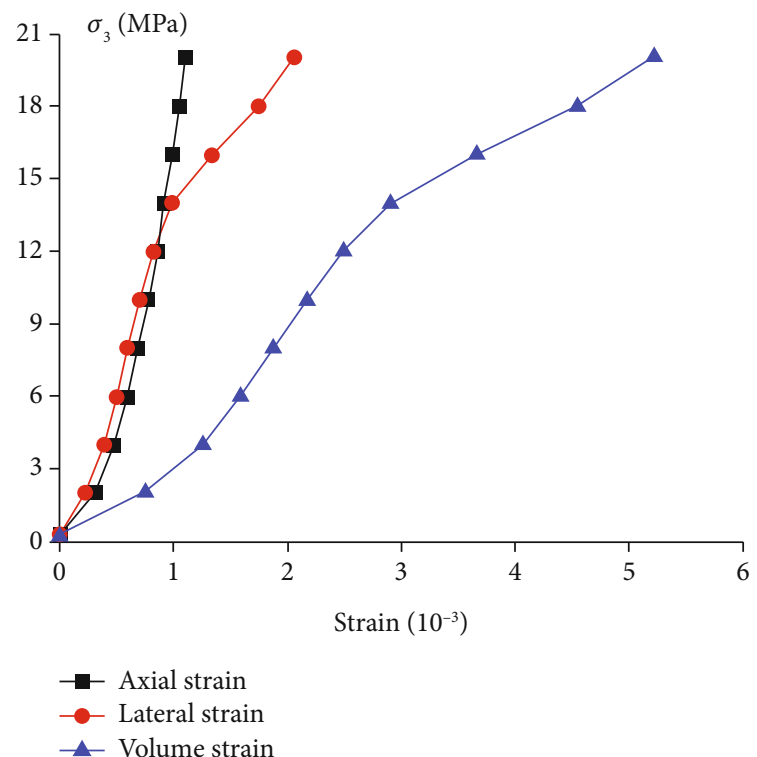

(a)

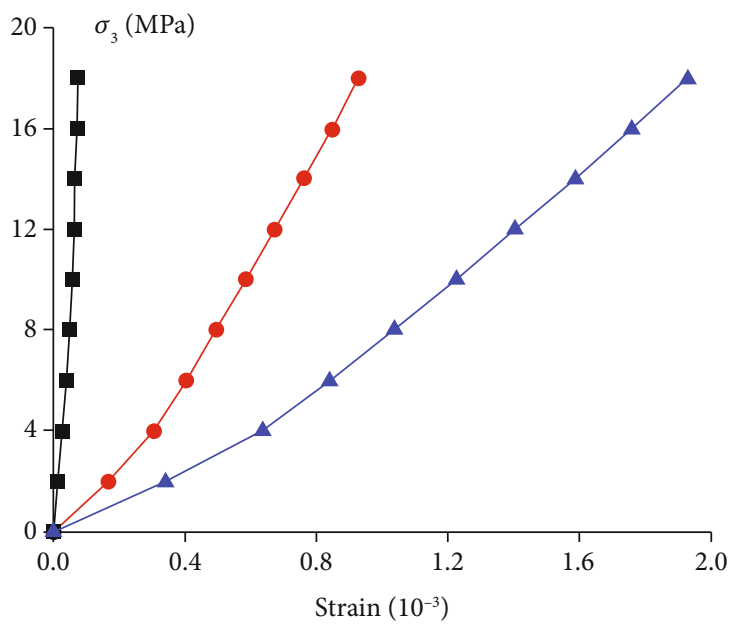

Axial strain

Lateral strain

- Volume strain

(b)

Figure 7: Hydrostatic tests results for SY-12. (a) Stress-strain curve under drained condition. (b) Stress-strain curve under undrained condition.

of $1 \mathrm{MPa}$, and the internal friction angle increased by $43.87 \%$. The cohesion at a pore pressure of $3 \mathrm{MPa}$ reduced by $36.49 \%$ compared to that with a pore pressure of $0 \mathrm{MPa}$, and the internal friction angle increased by $6.09 \%$. The reason was that pore pressure destroyed the connections in the internal structure and had a lubricating effect on the particle cement, and the cohesion of the sample was more sensitive to pore pressure, which led to a decrease in cohesion.
Under a high confining pressure of $15 \mathrm{MPa}$, the fitting curve showed a downward trend, which meant that with an increase in pore pressure, the effect of pore pressure on the peak strength was smaller. Under a confining pressure of $15 \mathrm{MPa}$, the high confining pressure compressed the inside of the sample more and reduced its water permeability. At that point, the effect of pore pressure on the peak strength was less than that under a low confining pressure, showing a slowing trend of peak strength. 


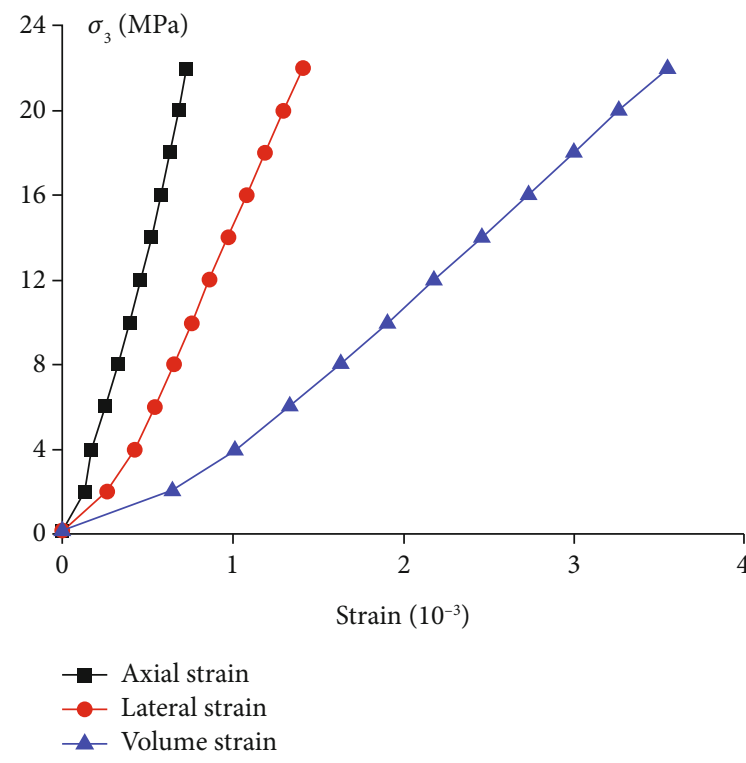

(a)

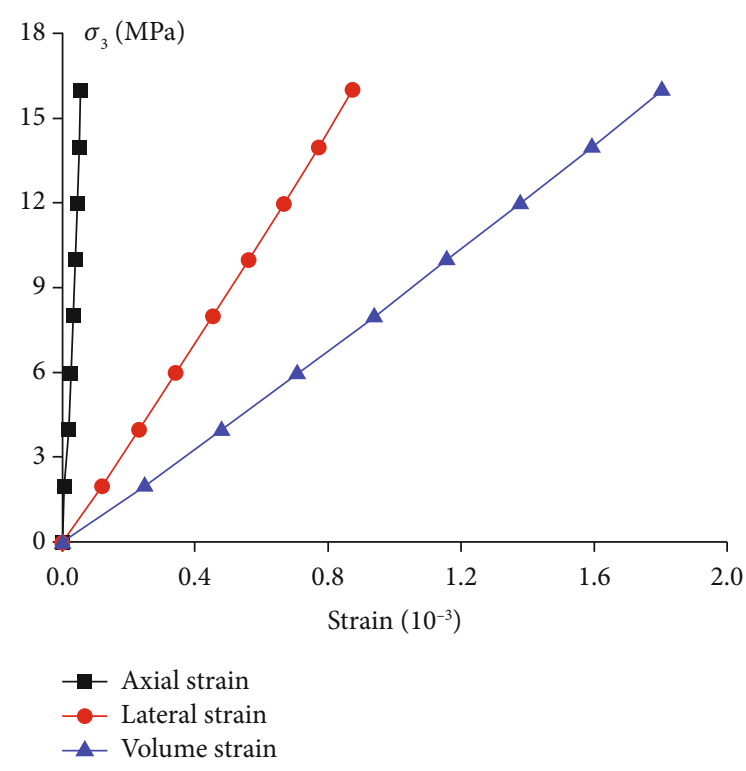

(b)

Figure 8: Hydrostatic tests results for SY-13. (a) Stress-strain curve under drained condition. (b) Stress-strain curve under undrained condition.

TABLE 4: The bulk modulus and the initial Biot coefficient.

\begin{tabular}{lccc}
\hline Number & $K_{\mathrm{b}}(\mathrm{MPa})$ & $K_{s}(\mathrm{MPa})$ & $b$ \\
\hline SY-11 & 5101.5 & 10037 & 0.492 \\
SY-12 & 5190.9 & 10846 & 0.521 \\
SY-13 & 5382.7 & 8897.1 & 0.395 \\
\hline
\end{tabular}

During the test, cracks initiated and expanded, and microcracks in the samples went through four stages: a compaction stage with crack closure (OA), an expansion stage with linear elastic deformation $(\mathrm{AB})$, an interpenetration stage with stable crack propagation (BC), and a destruction stage with unstable crack propagation (CD) [30]. Figure 4 shows the stages. In those initials, A stands for crack closure stress $\sigma_{c c}, \mathrm{~B}$ stands for crack initiation stress $\sigma_{c i}$, C stands for expansion stress $\sigma_{c d}$, and D stands for peak strength $\sigma_{c}$.

Crack closure stress corresponds to the stress value of the primary porosity of rock when the primary pores are completely compressed, which marks the turning point in the transition from the initial compaction stage to the line elastic stage. Crack closure stress can be approximated through the stress-strain curve, but if the turning point is determined by the subjective judgment of observers, the influence of human factors is too great. To determine the rock closure stress more accurately, this study used the method of axial strain difference proposed by Lu [15].

Crack closure stress could be calculated under each stress state, as shown in Table 2. The study of Jun et al. [31] showed that the number of cracks in rock was related to the closing stress: the more microcracks there were, the greater the load required to close them. Table 2 shows that crack closure stress increased approximately as the confin- ing pressure increased because in tests, the confining pressure loaded before the deviatoric stress. In the present study, before loading the deviatoric stress, the internal fractures of samples were compressed vertically under lateral compression. During loading deviatoric stress, the samples were squeezed at both ends to produce lateral cracks; as the deviatoric stress increased, the direction of compaction changed, and that changing value was called crack closure stress.

Eberhardt [30] proposed the stress threshold value of crack growth process, which meant rock crack initiation stress $\sigma_{\mathrm{ci}}$ and expansion stress $\sigma_{\mathrm{cd}}$. The crack initiation stress $\sigma_{\mathrm{ci}}$ indicated that internal cracks and crack growth in the rock were stable, which meant that if the stress level was constant, the cracks would not continue to expand, so the crack initiation stress is also known as the crack initiation point. Expansion stress $\sigma_{c d}$ is a sign of rock shear expansion. At that time, the internal rock cracks are unstable; that is, as stress continues to be applied, the cracks continue to expand until the unstable crack growth initiation point.

To determine the crack initiation stress $\sigma_{\mathrm{ci}}$ and expansion stress $\sigma_{\mathrm{cd}}$, Martin [32] proposed the concept of crack volumetric strain $\varepsilon_{\mathrm{cv}}$. In accordance with his method, the curve of crack initiation stress $\sigma_{\mathrm{ci}}$ and expansion stress $\sigma_{\mathrm{cd}}$ could be determined as shown in Table 2, which reflected the ratio of sandstone crack initiation stress $\sigma_{\mathrm{ci}}$ and peak intensity as $0.471: 0.615$, and ratios under various other stresses were close. It also showed that the influence of pore pressure on the rock failure process was manifested mainly in the process of acceleration from unstable crack propagation to failure.

Table 2 shows that, for the same pore pressure, the ratio of $\sigma_{c d}: \sigma_{c}$ increased as the confining pressure increased and that, for the same confining pressure, the ratio of $\sigma_{\mathrm{cd}}: \sigma_{\mathrm{c}}$ 


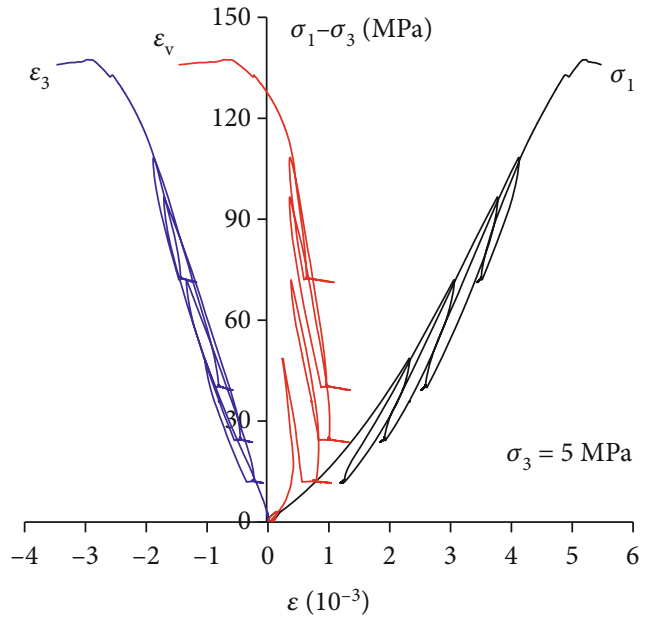

(a)

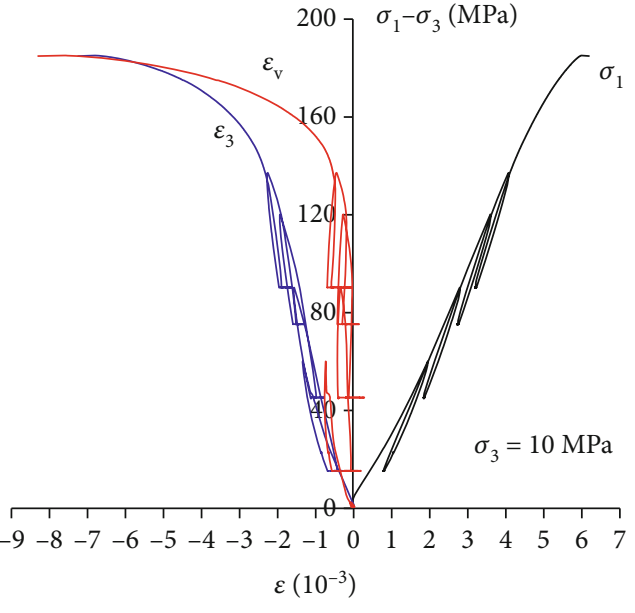

(b)

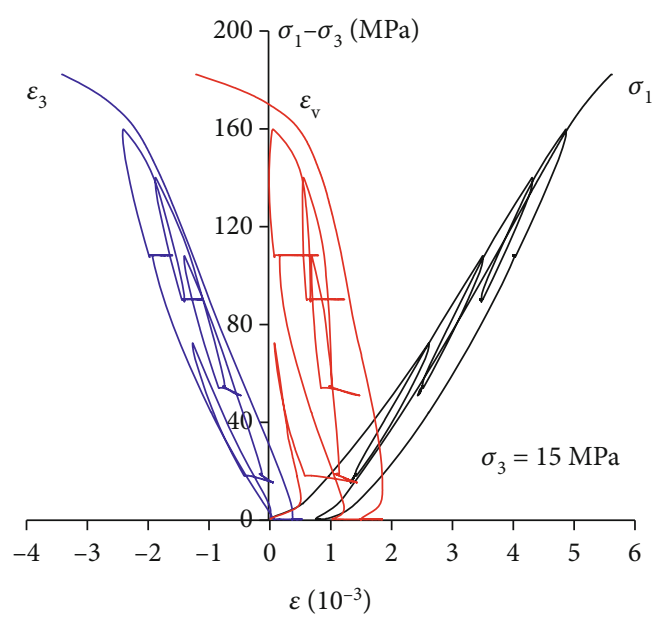

(c)

Figure 9: The complex cyclic loading and unloading tests results. (a) $\sigma_{3}=5 \mathrm{MPa}$. (b) $\sigma_{3}=10 \mathrm{MPa}$. (c) $\sigma_{3}=15 \mathrm{MPa}$.

TABLE 5: Test program and specific parameters.

\begin{tabular}{|c|c|c|c|c|c|c|c|}
\hline Sample number & $\sigma_{3}(\mathrm{MPa})$ & Assumed $\sigma_{c}$ & Stress level & $\sigma_{1}-\sigma_{3}$ load/unload (MPa) & $\sigma_{3}$ load/unload (MPa) & $\sigma_{c}(\mathrm{MPa})$ & $\varepsilon_{c}$ \\
\hline \multirow{4}{*}{ SY-11 } & \multirow{4}{*}{5} & \multirow{4}{*}{120} & 1 & $48 / 12$ & $8 / 5$ & \multirow{4}{*}{137.40} & \multirow{4}{*}{5.230} \\
\hline & & & 2 & $72 / 36$ & $8 / 5$ & & \\
\hline & & & 3 & $96 / 60$ & $8 / 5$ & & \\
\hline & & & 4 & $108 / 72$ & $8 / 5$ & & \\
\hline \multirow{4}{*}{ SY-12 } & \multirow{4}{*}{10} & \multirow{4}{*}{150} & 1 & $60 / 15$ & $15 / 10$ & \multirow{4}{*}{185.11} & \multirow{4}{*}{5.990} \\
\hline & & & 2 & $90 / 45$ & $15 / 10$ & & \\
\hline & & & 3 & $120 / 75$ & $15 / 10$ & & \\
\hline & & & 4 & $135 / 90$ & $15 / 10$ & & \\
\hline \multirow{4}{*}{ SY-13 } & \multirow{4}{*}{15} & \multirow{4}{*}{180} & 1 & $72 / 18$ & $20 / 15$ & \multirow{4}{*}{182.22} & \multirow{4}{*}{5.620} \\
\hline & & & 2 & $108 / 54$ & $20 / 15$ & & \\
\hline & & & 3 & $144 / 90$ & $20 / 15$ & & \\
\hline & & & 4 & $162 / 108$ & $20 / 15$ & & \\
\hline
\end{tabular}




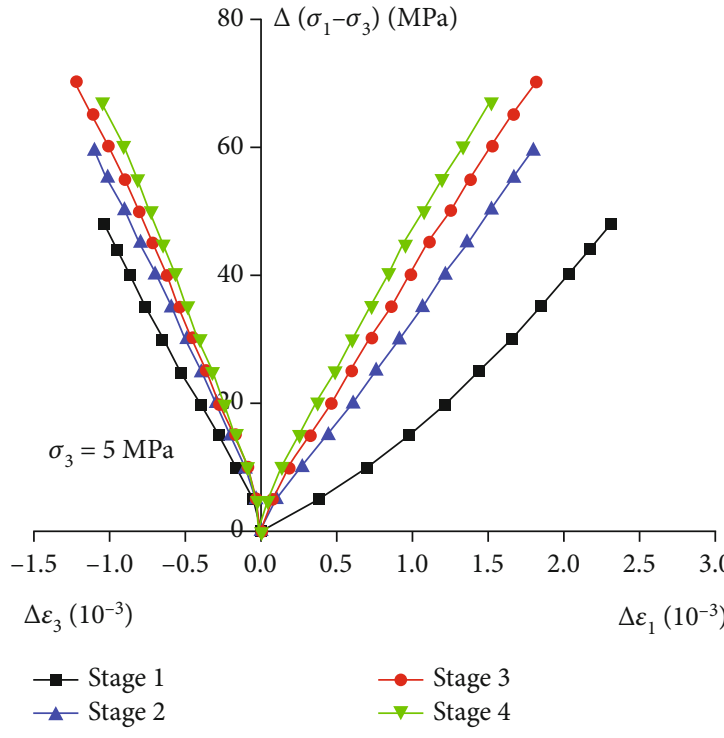

(a)

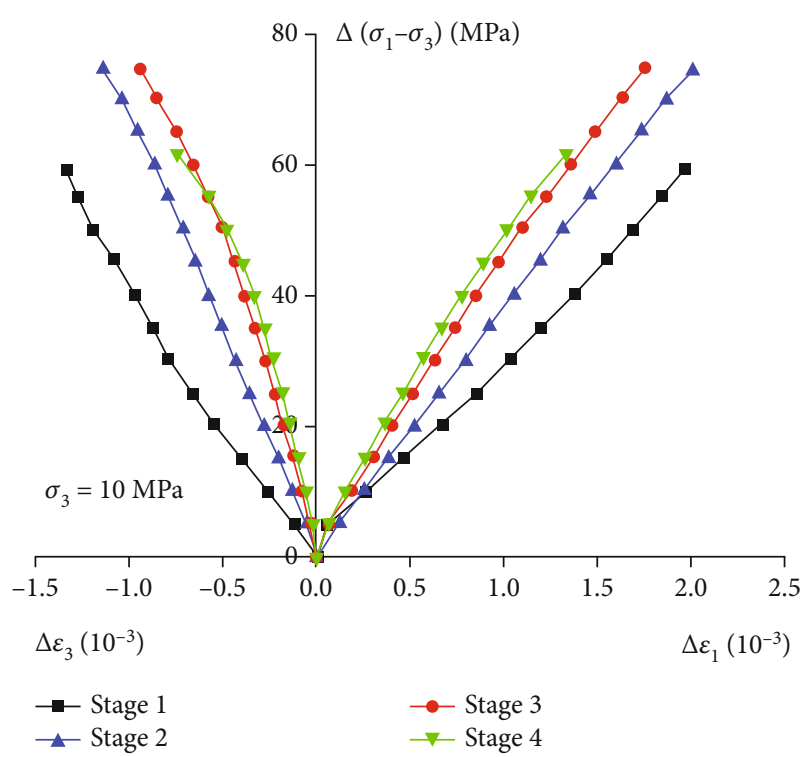

(b)

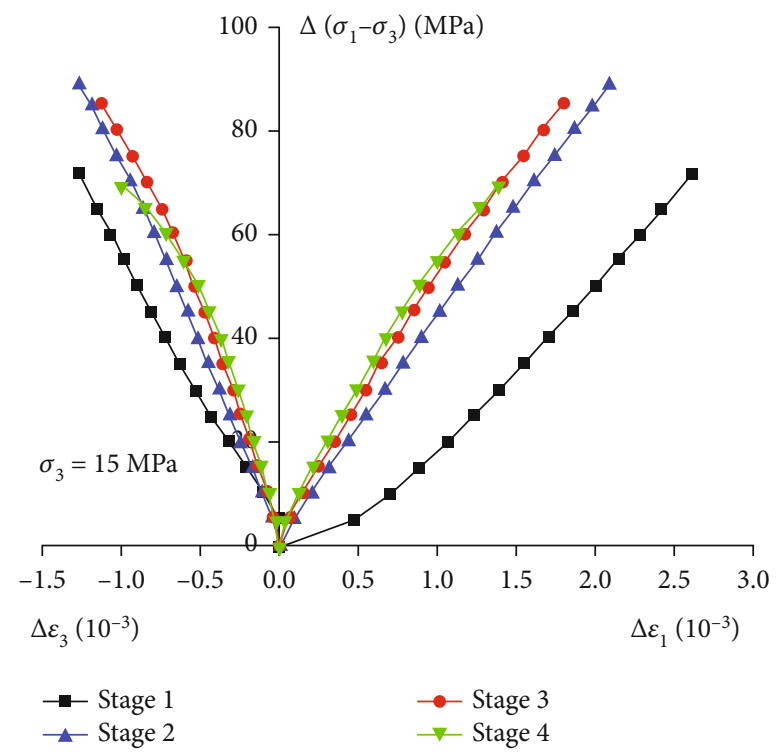

(c)

Figure 10: $\Delta\left(\sigma_{1}-\sigma_{3}\right)-\Delta \varepsilon$ curve in the loading stage. (a) $\sigma_{3}=5 \mathrm{MPa}$. (b) $\sigma_{3}=10 \mathrm{MPa}$. (c) $\sigma_{3}=15 \mathrm{MPa}$.

increased as the pore pressure increased. With the increase in confining pressure, $\sigma_{\mathrm{cd}}: \sigma_{c}$ tended to be constant, and high confining pressure also reduced the difference between the expansion stress and peak intensity. The compressive failure of the rock under high confining pressure was a shear failure in the unstable stage of crack growth.

For the same pore pressure, rock crack initiation stress $\sigma_{c i}$ and expansion stress $\sigma_{c d}$ increased as the confining pressure increased, indicating that the confining pressure effectively inhibited the internal crack propagation. For the same confining pressure, $\sigma_{\mathrm{ci}}$ and $\sigma_{\mathrm{cd}}$ increased as the pore pressure increased, which generally showed a downward trend, indicating that when the stress achieved $\sigma_{\text {ci }}$, some of the pore water permeated into cracks, which led to a rock crack propagation threshold in advance. When the stress reached $\sigma_{c d}$, the sandstone internal cracks were in the largest expansion stage, internal tensile cracks were the most developed, and macroscopic shear bands are formed. Under high pore pressure, water entered the samples, changed the internal structure, and weakened the mechanical properties. As the pore pressure increased, the softening effect was stronger. It was found that the increasing confining pressure effectively increased crack initiation stress $\sigma_{\mathrm{ci}}$ and expansion stress $\sigma_{\mathrm{cd}}$. The pore pressure on the crack initiation stress and the militancy stress change rates were smaller and had an irregular change trend; of course, this also had a certain relation with the pore pressure value. 


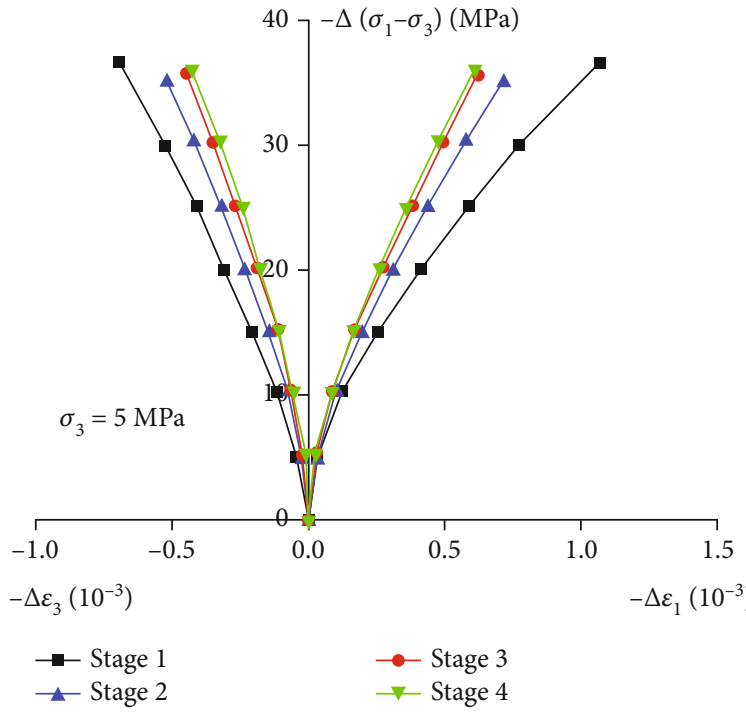

(a)

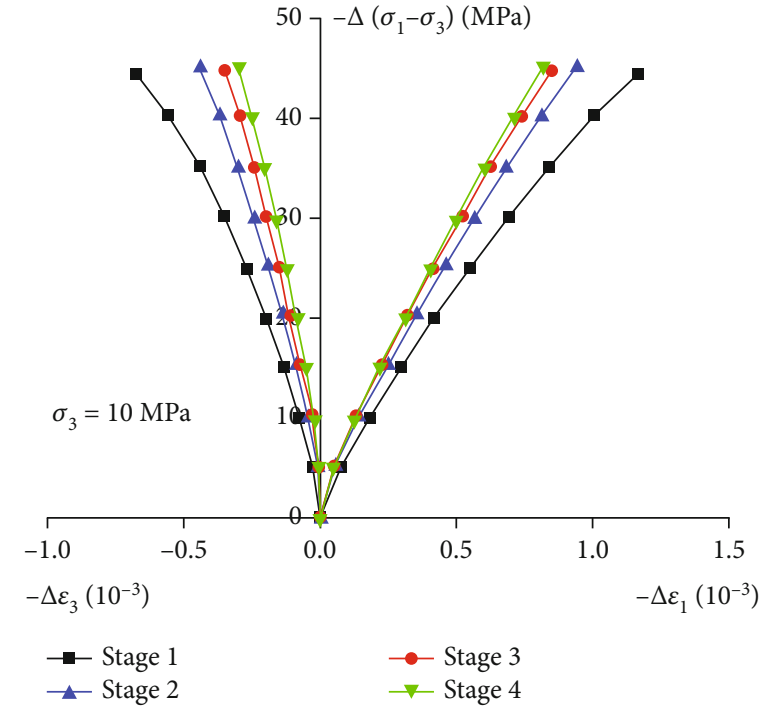

(b)

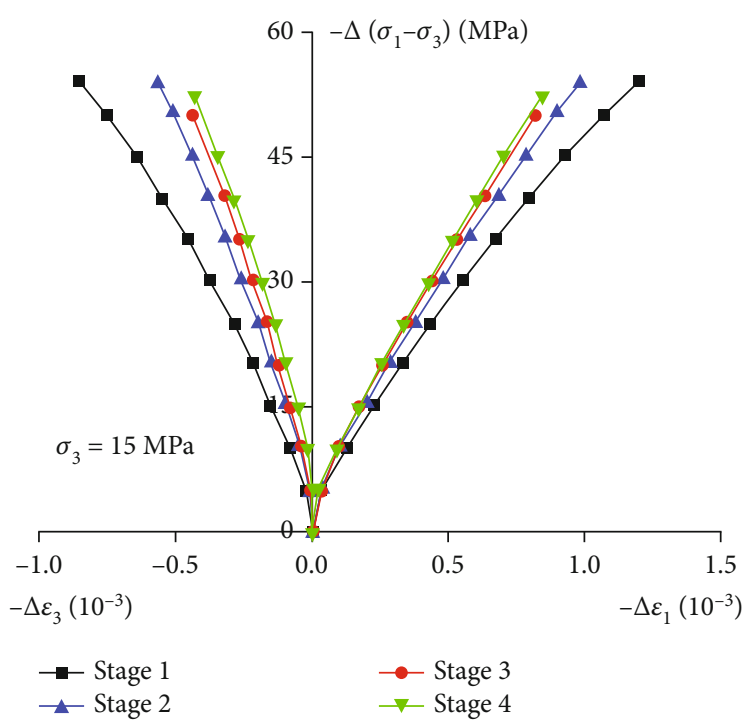

(c)

Figure 11: $\Delta\left(\sigma_{1}-\sigma_{3}\right)-\Delta \varepsilon$ curve in the unloading stage. (a) $\sigma_{3}=5 \mathrm{MPa}$. (b) $\sigma_{3}=10 \mathrm{MPa}$. (c) $\sigma_{3}=15 \mathrm{MPa}$. 
TABLE 6: The deformation parameters in each stage of deviatoric stress cycle.

\begin{tabular}{lccccccc}
\hline & & \multicolumn{3}{c}{ Loading } & \multicolumn{3}{c}{ Unloading } \\
Sample number & Stage & El1 & El3 & $\mu \mathrm{c}$ & Eul & Eu3 & $\mu \mathrm{u}$ \\
& & GPa & GPa & $\mu l$ & GPa & GPa & \\
\hline \multirow{3}{*}{ SY-11 } & 1 & 25.37 & 44.55 & 0.562 & 28.19 & 46.68 & 0.624 \\
& 2 & 32.27 & 51.77 & 0.653 & 34.78 & 50.92 & 0.702 \\
& 3 & 37.35 & 55.37 & 0.681 & 42.16 & 58.15 & 0.728 \\
& 4 & 41.68 & 61.75 & 0.691 & 48.18 & 69.93 & 0.697 \\
\hline \multirow{3}{*}{ SY-12 } & 1 & 28.17 & 50.05 & 0.638 & 35.10 & 57.80 & 0.589 \\
& 2 & 37.24 & 66.61 & 0.562 & 43.91 & 88.94 & 0.486 \\
& 3 & 42.32 & 79.95 & 0.554 & 48.38 & 107.8 & 0.436 \\
& 4 & 46.44 & 85.87 & 0.549 & 50.12 & 121.8 & 0.387 \\
\hline \multirow{3}{*}{ SY-13 } & 1 & 32.30 & 53.42 & 0.604 & 41.71 & 58.27 & 0.714 \\
& 2 & 42.29 & 70.22 & 0.612 & 50.02 & 84.47 & 0.584 \\
& 3 & 46.66 & 75.15 & 0.637 & 54.50 & 98.14 & 0.540 \\
& 4 & 49.23 & 70.45 & 0.733 & 56.21 & 100.8 & 0.538 \\
\hline
\end{tabular}

3.2. Analysis of Rock Damage Evolution. There are many defects and cracks in rock, and the evolution of fracture damage occurs in the process of compressive failure. Krajcinovic and Silva [33] assumed that the rock microunit strength satisfied a Weibull random distribution, starting from the random nature of the defects, such as cracks and pores in the material, and combined the statistical theory and damage mechanics to establish a statistical damage equation:

$$
D=1-\exp \left(-\left(\frac{\varepsilon}{\varepsilon_{0}}\right)^{m}\right)
$$

where $D$ is a damage variable, $\varepsilon$ is strain, and $m$ and $\varepsilon_{0}$ are parameters of the Weibull distribution. In the present study, in accordance with the characteristics of the peak stress and strain curve, a simple method of determining the parameters was derived:

$$
\left.\begin{array}{l}
m=\frac{1}{\ln \left(E \varepsilon_{c} / \sigma_{c}-2 \mu \sigma_{3}\right)} \\
\varepsilon_{0}=\varepsilon_{c} \cdot m^{1 / m}
\end{array}\right\},
$$

where $\sigma_{c}$ and $\varepsilon_{c}$ are peak stress and peak strain, respectively.

For analysis, the axial strain, damage variable, and axial deviatoric stress curves were drawn in the same graph (Figure 5). In the figure, point $A$ is the damage threshold, which means the damage started there; $\varepsilon_{t}$ is the rock damage threshold strain, which corresponds to the damage threshold stress $\sigma_{t}$; and point B is the inflection point of the damage evolution curve. From point B, the damage started to develop rapidly. The corresponding stress was the damage inflection point $\sigma_{d}$, and the corresponding strain was the damage inflection point $\varepsilon_{d}$.
Each stress value under various confining pressures and pore pressures was compared and analyzed. In accordance with the experiment curve, the threshold strain of the rock damage $\varepsilon_{t}$, the damage threshold stress $\sigma_{t}$, the inflection point of damage strain $\varepsilon_{d}$, and the damage inflection point stress $\sigma_{d}$ were determined, as shown in Table 3. The ratio of the damage inflection point stress $\sigma_{d}$ and the peak strength $\sigma_{c}$ was ranged from 0.82 to 0.89 , and the damage inflection point stress was less than the expansion stress, which indicates that the time of the damage into the high-speed development period was earlier than the time when the rock volume expanded, and damage inflection point stress was a sign of volume expansion failure. When deviatoric stress was loading to damaged inflection point stress $\sigma_{d}$, the crack propagation speed was more rapid than it was in the elastic stage, while rock material yielding and damage increase rapidly. The curve showed an obvious trend of a turning point for injury, so it could be concluded that the inflection point of damage is an important parameter to determine whether rock would yield.

\section{Results of Complex Cyclic Loading and Unloading Tests}

In order to study the mechanical characteristics of the rock under the complex stress conditions, hydrostatic pressure test and complex cycle loading and unloading test were done on samples SY-11 to SY-13.

4.1. Hydrostatic Test. The hydrostatic pressure tests were done with samples SY-11 to SY-13, and the hydrostatic pressure-strain curves for three samples under different drainage conditions are shown in Figures 6-8, respectively.

It could be seen from the figure that both axial strain and lateral strain exhibit nonlinear compaction characteristics during the initial loading stage, which is caused by the initial microcracks and the gradual pore closure. In Figure 6(a), when the hydrostatic pressure was loaded to $5 \mathrm{MPa}$, the axial and lateral strain curves entered the linear elastic stage. This linear stage could reflect the elastic behavior. According to the slope of the volumetric strain curve in the linear elastic stage, the bulk modulus $K_{\mathrm{b}}$ could be obtained. Also, in Figure $6(\mathrm{~b})$, we could see when the hydrostatic pressure was loaded to $6 \mathrm{MPa}$, the axial and lateral strain curves entered the linear elastic stage. According to the slope of the volumetric strain curve in the linear elastic stage, the solid matrix bulk modulus $K_{\mathrm{s}}$ could be obtained.

In Nur and Byerlee's paper [34], the Biot coefficient is measured as below:

$$
b=1-\frac{K_{\mathrm{b}}}{K_{\mathrm{s}}}
$$

Here, $b$ is Biot's coefficient, $K_{b}$ is the skeleton bulk modulus, and $K_{s}$ is the solid matrix bulk modulus. The skeleton bulk modulus, solid matrix bulk modulus, and initial Biot coefficient for each sample are shown in Table 4. 


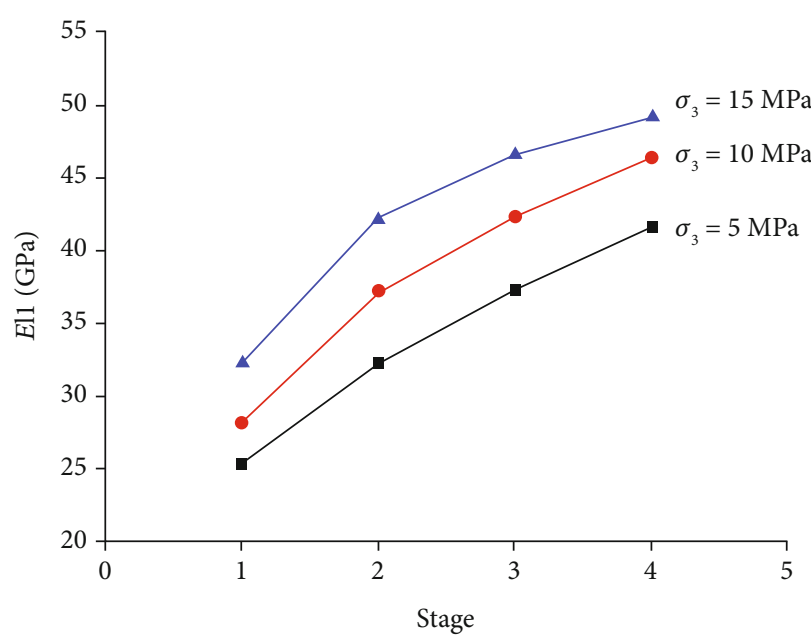

(a)

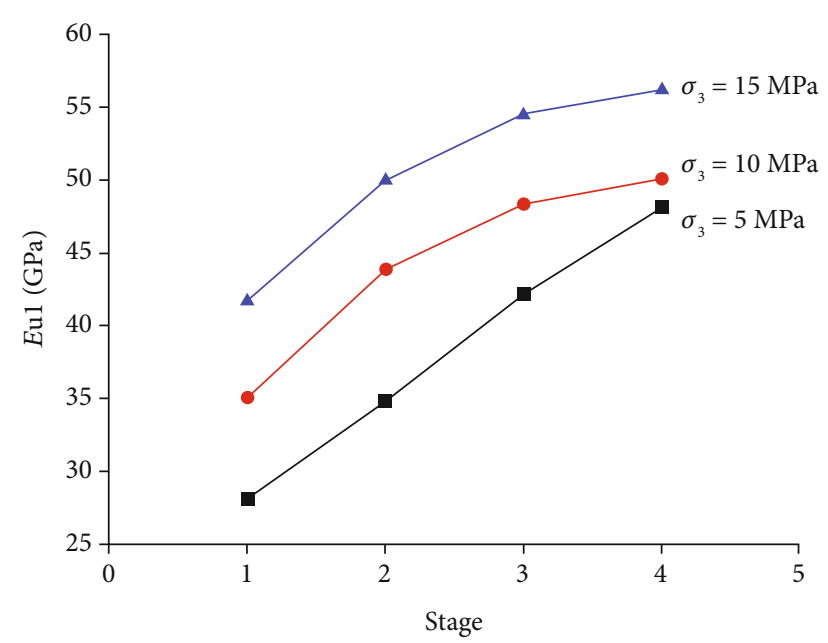

(b)

FIgURE 12: Axial elastic modulus evolution. (a) Loading stage. (b) Unloading stage.

It was believed that the Biot coefficient was closely related to the mineral composition and internal structure, such as particle size, arrangement, and particle shape [35]. The Biot coefficient could reflect the material pore stiffness. The larger the Biot coefficient, the softer the pore medium skeleton. It could be seen that the Biot coefficients of SY-11 and SY-12 are relatively close, while the Biot coefficient of SY-13 is smaller, which showed that there were certain differences in the original internal structure of the three rock samples.

4.2. Results of Complex Cyclic Loading and Unloading Tests. The Biot coefficient could reflect the material pore stiffness. The larger the Biot coefficient, the softer the pore medium skeleton. It could be seen that the Biot coefficients of SY-11 and SY-12 are relatively close, while the Biot coefficient of SY-13 is smaller, which showed that there were certain differences in the original internal structure of the three rock samples. The samples SY-11 to SY-13 were conducted with the complex cyclic loading and unloading tests under confining pressure of $5 \mathrm{MPa}, 10 \mathrm{MPa}$, and $15 \mathrm{MPa}$, respectively. The results are shown in Figure 9, and the parameters are shown in Table 5.

By analyzing Figure 9, it could be found that the loading and unloading curves of axial, lateral, and volumetric strains under same stage cycle did not overlap, and the unloading curve and the loading curve of the next stage cycle did not overlap as well. As the stages increased, the hysteresis loop composed of axial stress-strain loading and unloading curves continued to move forward. The stress-strain curve of each level was not a straight segment, but a concave shape, and the unloading curve was more obvious. This was because the rock continuously undergone compaction and expansion during the test. When the external load exceeded its elastic limit, the internal microcracks began to expand. During the unloading process, due to the continuous expansion of the previous microcracks, a concave phenomenon of the stress-strain curve would appear. The new microcracks in the next stage of loading were recompacted, and when the load exceeded the ultimate strength of the upper-level loading, the microcracks continued to expand, and the stressstrain curve appeared concave again.

4.2.1. Analysis of Deviatoric Stress Loading-Unloading Cycles. In order to study the influence of deviatoric stress on rock strength and deformation, the deviatoric stress increment $\left(\Delta \sigma=\sigma-\sigma_{0}\right)$ with the axial and lateral strains increment $\left(\Delta \varepsilon=\varepsilon-\varepsilon_{0}\right)$ curves is shown in Figures 10 and 11 .

In Figures 10 and 11, each curve could be divided into two sections, the initial nonlinear section and the elastic straight section. The slope of the first-level loading curve was obviously smaller than the next loading curves. As the loading level increased, the curves tended to overlap, indicating that the internal cracks closed under high stress, and the deformation trended to be smaller.

The deformation parameters in each stage are shown in Table 6. In the table, El1 and El3 were, respectively, axial and lateral elastic moduli in loading stage, and Eu1 and Eu3 were, respectively, axial and lateral elastic moduli in unloading stage. $\mu \mathrm{l}$ and $\mu \mathrm{u}$ were, respectively, Poisson|' ratio in loading and unloading stage.

The results showed that in each cyclic stage, Eul is greater than El1; this is because for each level, the deviatoric stress induced partial plastic deformation and the axial deformation in unloading process is smaller than that in reloading process.

The evolution of elastic modulus with loading stage is shown in Figures 12 and 13. In Figure 12, the axial elastic modulus of the first stage of loading increased significantly, and the increasing trend of the subsequent stages slowed down. Under $15 \mathrm{MPa}$ confining pressure, compared to last stage, El1 increased $30.93 \%, 10.33 \%$, and $5.51 \%$, because after the first cycle, the internal cracks were 


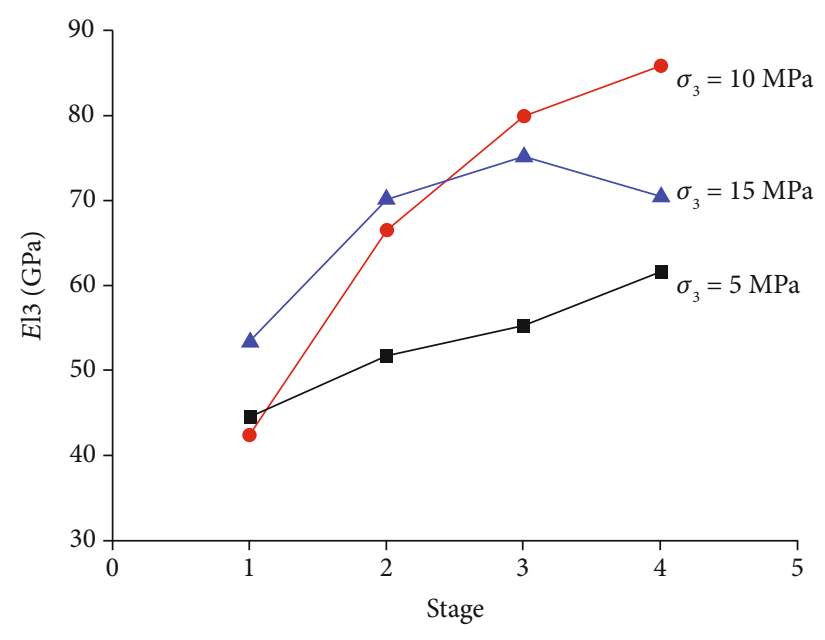

(a)

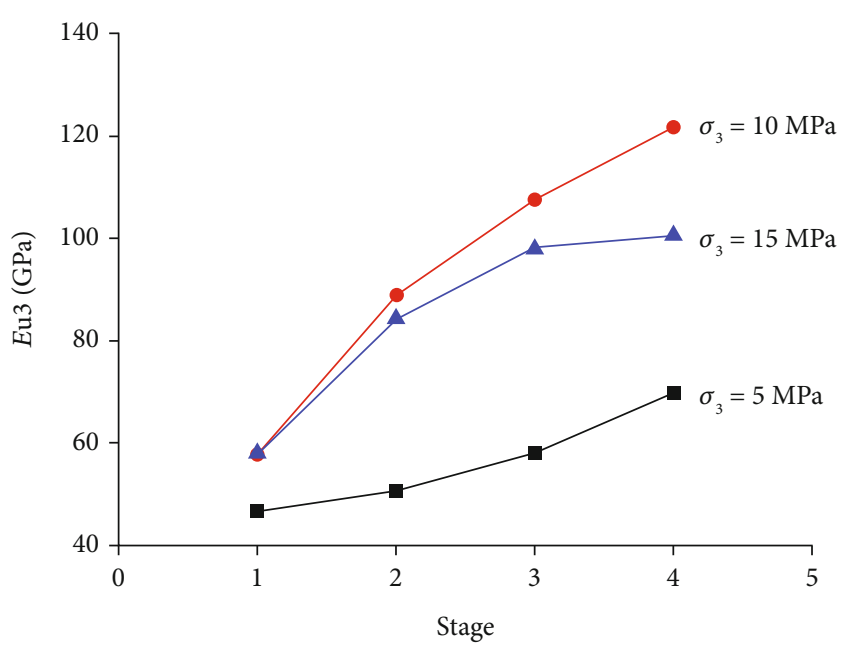

(b)

FIGURE 13: Lateral elastic modulus evolution. (a) Loading stage. (b) Unloading stage.

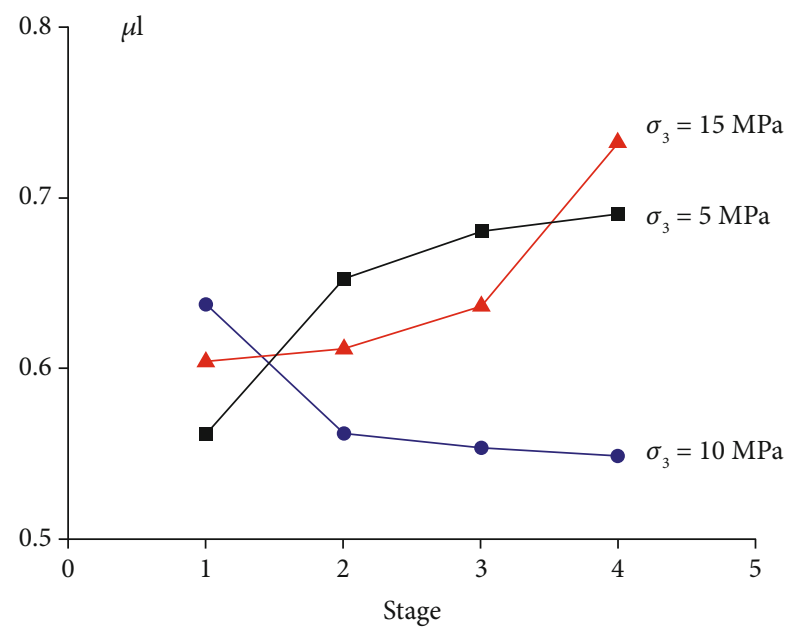

FIGURE 14: $\mu$ l-stage level curve.

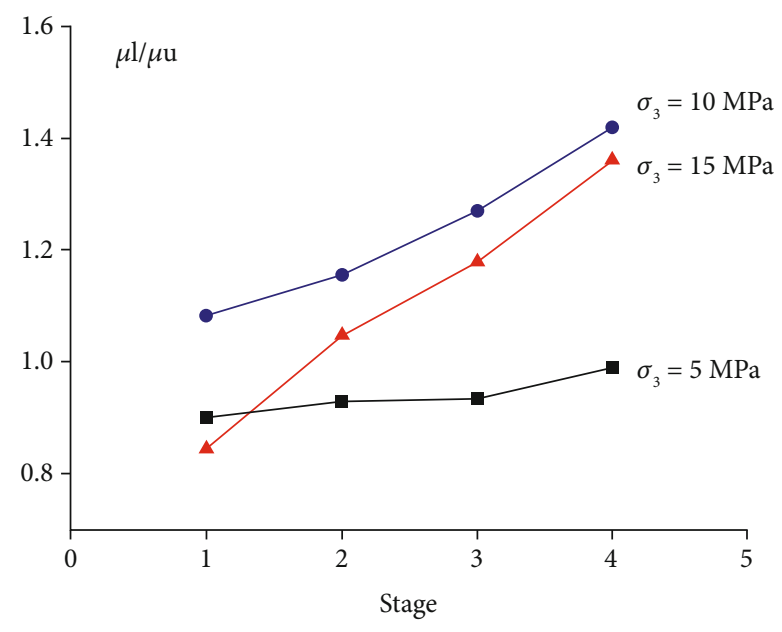

FIgURE 15: $\mu \mathrm{l}: \mu \mathrm{u}$-stage level curve. compacted, and initial plastic strain was generated. These compacted defects would not rebound the elastic modulus that appeared to be strengthened; when the rock undergone the first strengthening cycle, the internal microcracks and pores were compacted. During the next stages, the rock skeleton was compressed as well. But due to the large rigidity of the rock skeleton, the compacting effect gradually decreased, so the increasing trend of the axial elastic El1 slowed down.

In Figure 13(a), under $5 \mathrm{MPa}$ and $10 \mathrm{MPa}$ confining pressure, we could see $E \mathrm{l} 3$ increased with loading stage increased, but for $10 \mathrm{MPa}$ confining pressure, the increasing trend in third and fourth stages was slowed down. For $15 \mathrm{MPa}$ confining pressure, El3 in fourth stage was lower than it in third stage, while El1 continued to increase as Figure 12 shows, indicating that crack grew earlier in lateral direction than in axial direction; in Figure 13(b), we could see the evolution of Eu3 was similar to El3 that Eu3 increased under lower confining pressure and decreasing at fourth stage under higher confining pressure.

The evolution of Passion's ratio is shown in Figure 14; we could see Poisson's ratio increased as loading stage increased, indicating that inner microcracks expanded with stress level increased. Figure 15 shows loading Poisson's ratio/unloading Poisson's ratio increased with stress level increased; the reason was that with the stage increased, the cracks were increasing, and the cracks were more and more difficult to recover during unloading process.

\subsubsection{Analysis of Confining Pressure Loading-Unloading} Cycles. In order to study the influence of confining pressure on rock strength and deformation, the confining pressure increment $\left(\Delta \sigma_{3}=\sigma_{3}-\sigma_{30}\right)$ with the axial and lateral strains increment $\left(\Delta \varepsilon=\varepsilon-\varepsilon_{0}\right)$ curves is shown in Figures 16 and 17. 


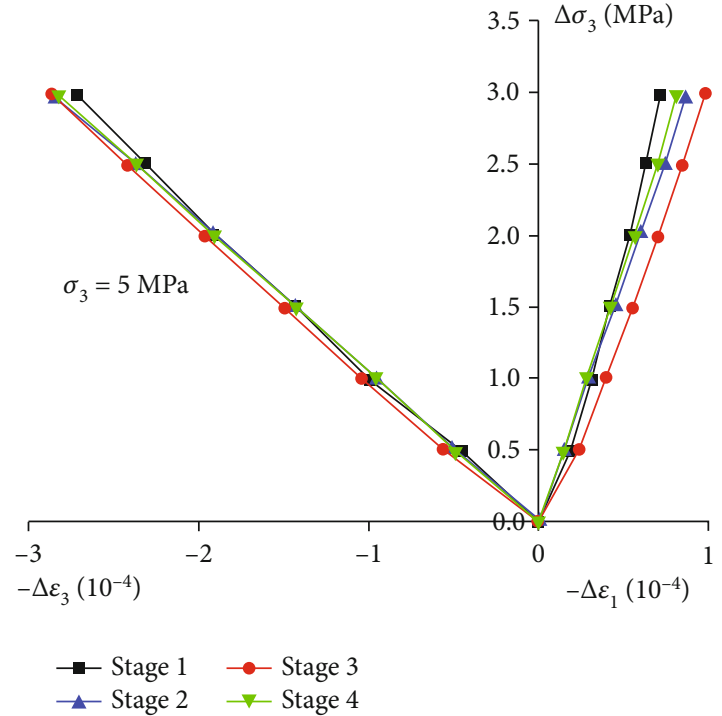

(a)

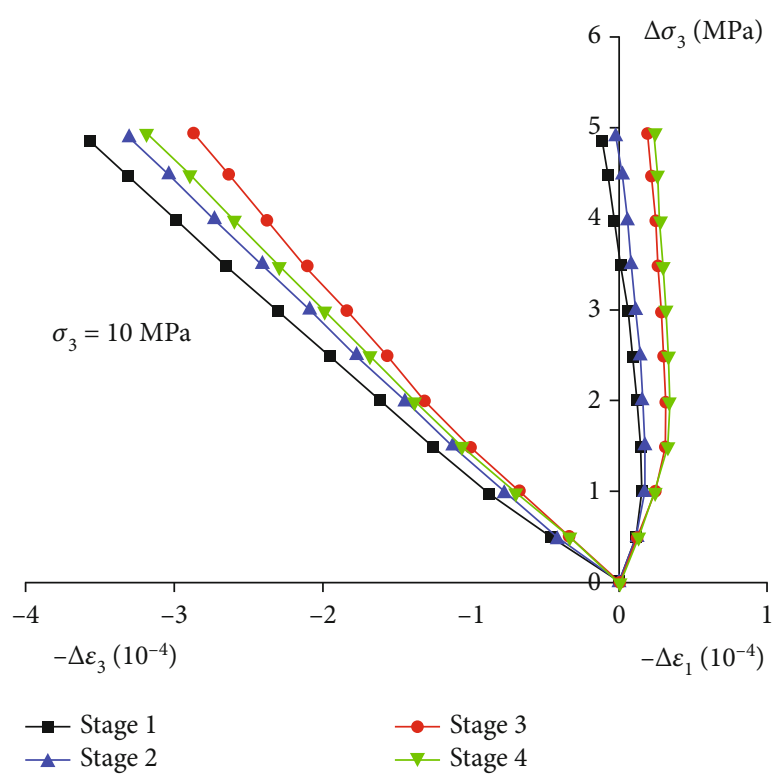

(b)

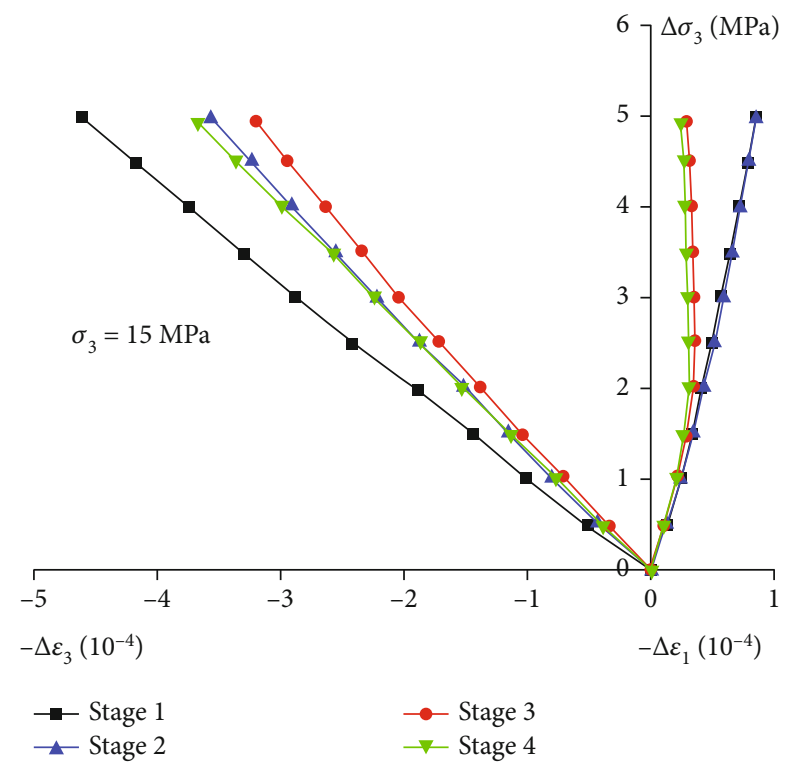

(c)

Figure 16: $\Delta \sigma_{3}-\Delta \varepsilon$ curve in loading stage. (a) $\sigma_{3}=5 \mathrm{MPa}$. (b) $\sigma_{3}=10 \mathrm{MPa}$. (c) $\sigma_{3}=15 \mathrm{MPa}$.

In Figure 16(a), the lateral strain curves at four levels under $5 \mathrm{MPa}$ confining pressure were almost overlapped, and deformation change was not obvious. In Figures 16(b) and 16(c), the lateral increment caused by the first three levels were gradually smaller, and the increased rebound phenomenon occurred in the fourth level, indicating that the sample was more and more difficult to shrink with the increase of the loading level in first three levels, and the internal damage occurred during the fourth level, and the lateral deformation rebounded and increased. In Figure 17, the lateral deformation caused by unloading process increased with stage increased, which showed opposite trend to loading stage, indicating that the strain difference between loading and unloading pro- cesses was constantly shrinking, because the initial plastic strain generated by compaction of original pores during first loading stage was relatively large, with the increase of loading stage, the internal compactness of the sample became higher, and its plastic deformation tended to be stable before the sample was broken.

(1) Analysis of Elastic Modulus. The lateral strain and confining pressure had good linear relationship; the deformation parameters El3 and Eu3 in each stage are shown in Table 7.

It could be seen that Eu3 was larger than El3 at each level. Figure 18 shows the relationship between El3 and loading stages under different confining pressures. Under 


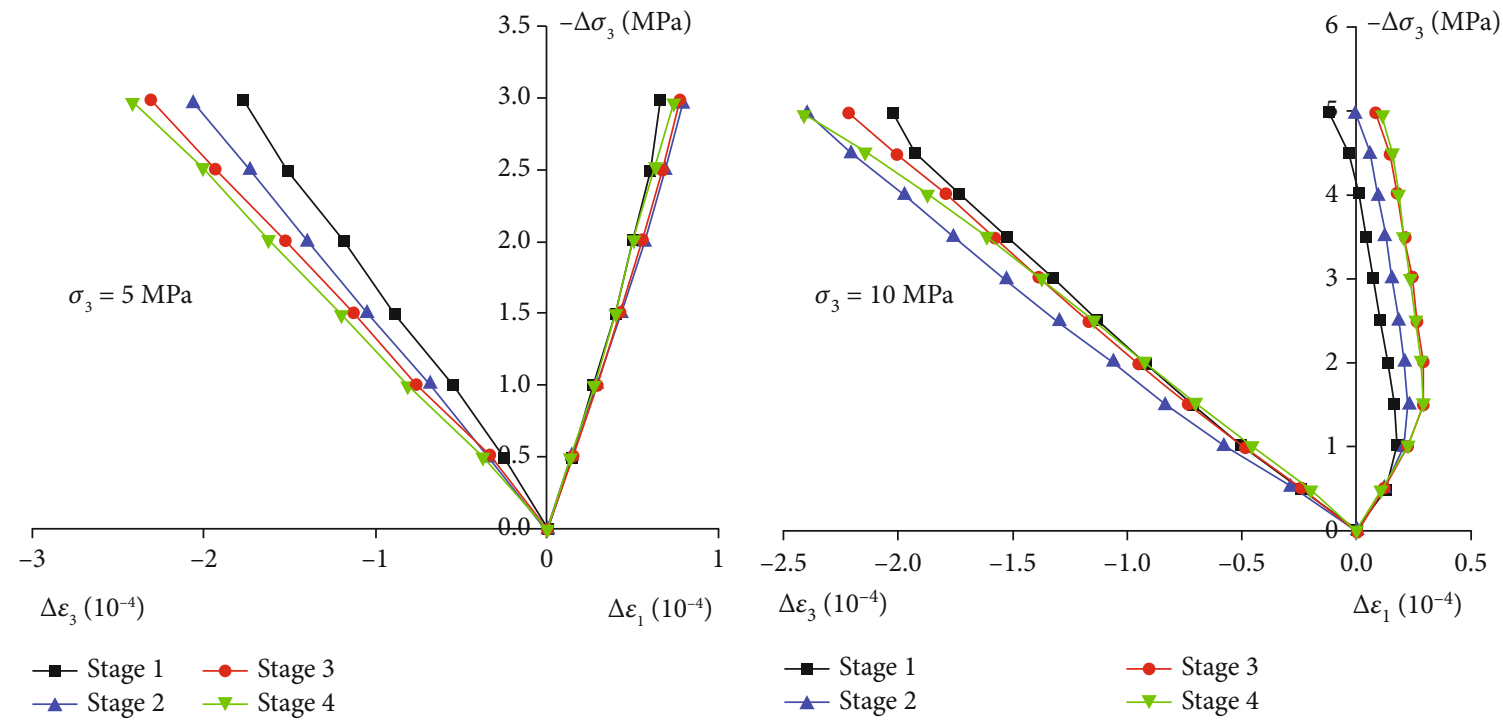

(a)

(b)

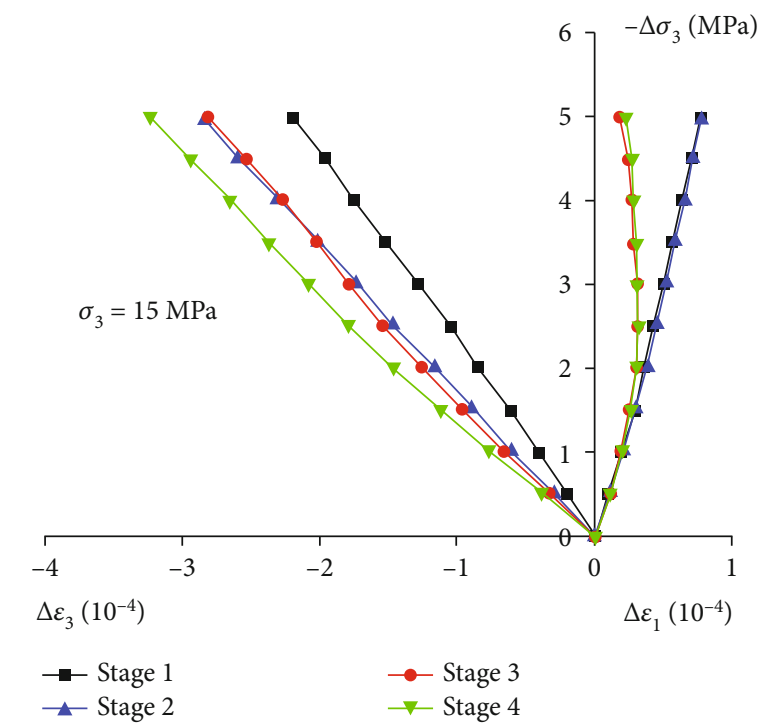

(c)

Figure 17: $\Delta \sigma_{3}-\Delta \varepsilon$ curve in unloading stage. (a) $\sigma_{3}=5 \mathrm{MPa}$. (b) $\sigma_{3}=10 \mathrm{MPa}$. (c) $\sigma_{3}=15 \mathrm{MPa}$. 
TABLE 7: The deformation parameters in each stage of confining pressure cycle.

\begin{tabular}{lccc}
\hline Sample number & Stage & $\begin{array}{c}\text { Loading } \\
\text { El3 } \\
\text { GPa }\end{array}$ & $\begin{array}{c}\text { Unloading } \\
\text { Eu3 } \\
\text { GPa }\end{array}$ \\
\hline \multirow{3}{*}{ SY-11 } & 1 & 10.91 & 16.45 \\
& 2 & 10.49 & 14.32 \\
& 3 & 10.60 & 12.80 \\
SY-12 & 4 & 10.57 & 12.33 \\
& 1 & 13.82 & 24.21 \\
& 2 & 15.04 & 20.97 \\
& 3 & 17.36 & 22.69 \\
SY-13 & 4 & 15.62 & 20.76 \\
& 1 & 10.84 & 22.55 \\
& 2 & 14.09 & 17.48 \\
& 3 & 15.46 & 18.00 \\
& 4 & 13.51 & 15.53 \\
\hline
\end{tabular}

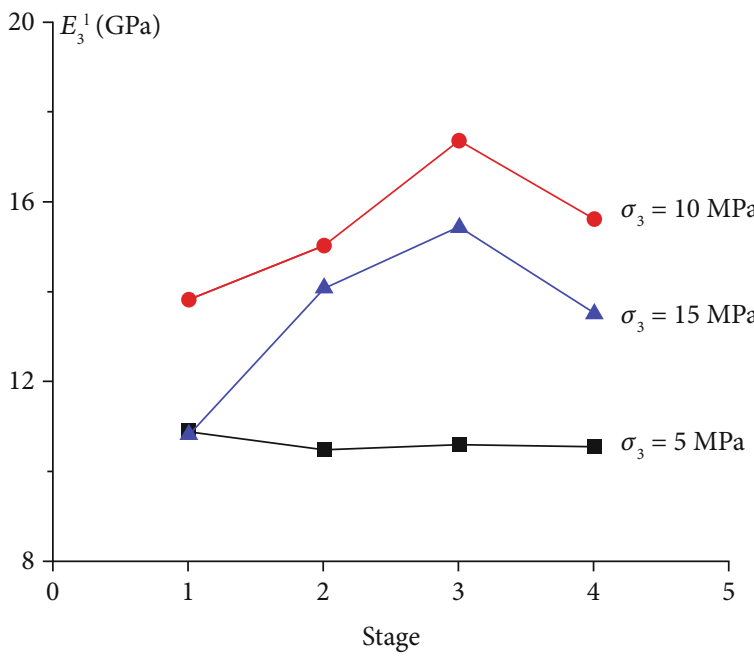

FIgURe 18: Lateral elastic modulus in loading stage.

$10 \mathrm{MPa}$ and $15 \mathrm{MPa}$ confining pressures, the lateral elastic modulus gradually increased in first three stages and dropped in the fourth stage, showing a first increasing and then decreasing trend. Figure 19 shows the relationship between Eu3 and unloading stages under different confining pressures. And Eu3 generally shows a constant decreasing trend. This was because the sample was at a certain deviatoric stress level when the confining pressure was doing loading-unloading cycles. Under first three levels of deviatoric stress loading and unloading cycles, it was still in elastic stage. When the fourth level was loaded, microcracks occurred and the confining pressure loading could cause greater lateral deformation and lateral elastic modulus dropped.

(2) Analysis of Biot Coefficient. During the test as confining pressure was subjected to loading and unloading cycles under drained condition, while the deviatoric stress and

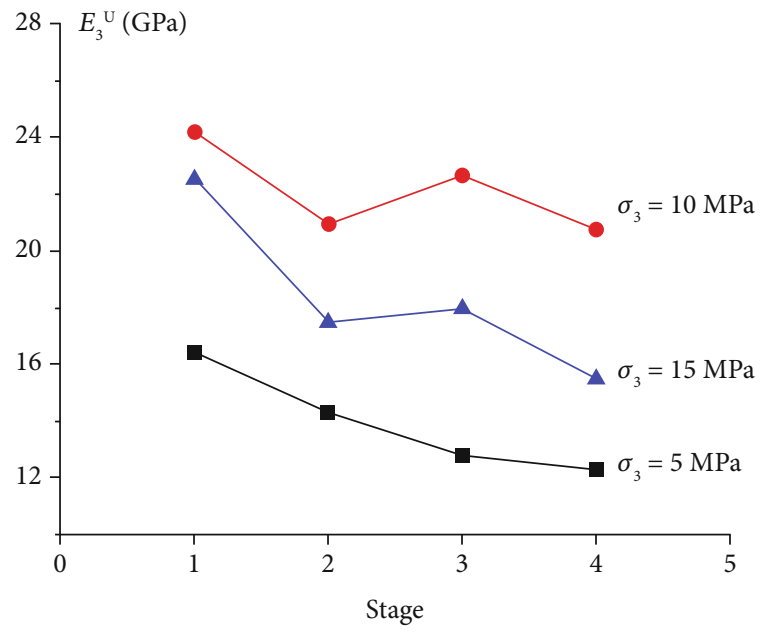

FIGURE 19: Lateral elastic modulus in unloading stage.

TABLE 8: Results of skeleton bulk modulus and the Biot coefficient at each stage.

\begin{tabular}{lcccc}
\hline Sample number & Stage & $K_{\mathrm{b}}(\mathrm{MPa})$ & $K_{\mathrm{s}}(\mathrm{MPa})$ & $b$ \\
\hline \multirow{4}{*}{ SY-11 } & 0 & 5101.5 & & 0.492 \\
& 1 & 6235.1 & & 0.379 \\
& 2 & 6196.6 & 10037 & 0.383 \\
& 3 & 6356.7 & & 0.367 \\
& 4 & 6199.7 & & 0.382 \\
\hline \multirow{3}{*}{ SY-12 } & 0 & 5190.9 & & 0.521 \\
& 1 & 6726.3 & & 0.379 \\
& 2 & 7401.2 & 10846 & 0.318 \\
& 3 & 8853.6 & & 0.185 \\
& 4 & 8004.9 & & 0.262 \\
\hline \multirow{4}{*}{ SY-13 } & 0 & 5382.8 & & 0.395 \\
& 1 & 5954.6 & & 0.331 \\
& 2 & 7983.9 & 8897.1 & 0.103 \\
& 3 & 8030.1 & & 0.097 \\
& 4 & 6936.2 & & 0.220 \\
\hline
\end{tabular}

pore pressure were kept constant, this situation could be considered the hydrostatic pressure loading under the drained condition. For a rock material formed by crystallization or cementation, the compressibility of the solid particles was very small, and the solid particles were generally considered incompressible, so $K_{\mathrm{s}}$ was regarded as a fixed value. According to Formula (3), the skeleton bulk modulus $K_{\mathrm{b}}$ and the Biot coefficient under each stage could be calculated. The calculation results are shown in Table 8 . In order to facilitate the comparison with the initial Biot coefficient, the result was expressed as stage 0 .

Figure 20 shows the Biot coefficient-stage curves for sample SY-11 SY-13, which showed the same trend. In first four stages, the Biot coefficients showed a decreasing trend, and in the fifth stage, the Biot coefficient increased. 


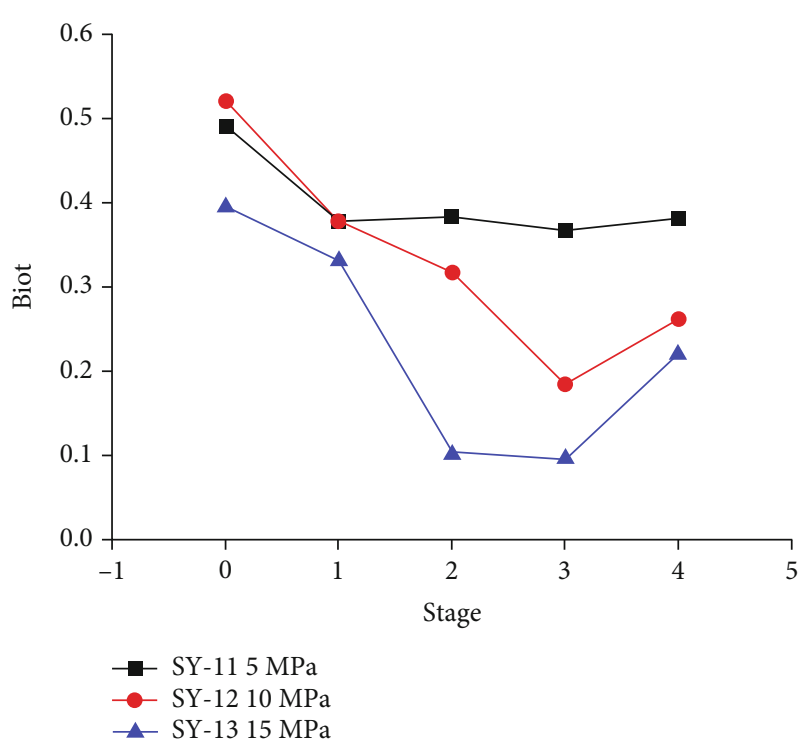

FIGURE 20: Variation curve of the Biot coefficient with loading stage.

This was because the Biot coefficient was closely related to the mineral composition and internal structure. The larger the Biot coefficient, the softer the porous medium framework. In first four stages, due to crack compaction and pore closure, the Biot coefficient showed a decreasing trend, while in the fifth stage, due to the continuous accumulation of internal damage, the initiation and continuous expansion of microcracks were induced, leading to an increasing Biot coefficient. It could also be seen from Figure 20 that in first four stages, the greater the confining pressure, the smaller the corresponding Biot coefficients at each level. For example, the Biot coefficient at each stage under $15 \mathrm{MPa}$ for SY-13 was obviously smaller than those under $5 \mathrm{MPa}$ and $10 \mathrm{MPa}$. The higher the confining pressure, the stronger the compaction degree, and the smaller the corresponding Biot coefficient.

\section{Conclusions}

In this study, conventional triaxial tests were conducted under drained condition. Moreover, hydrostatic compression tests under drained and undrained condition and complex cyclic loading and unloading tests were also carried out. The following conclusions were drawn:

(1) Confining pressure strengthened the restraint effect, and under the same pore pressure, elastic modulus $E$, peak strength $\sigma_{c}$, crack closure stress $\sigma_{\text {cc }}$, crack initiation stress $\sigma_{\mathrm{ci}}$, expansion stress $\sigma_{\mathrm{cd}}$, and the ratio of $\sigma_{c d}: \sigma_{c}$ increased with increasing confining pressure; there was a close linear relation. In a high confining pressure, pore pressure reduced the rock strength less. Under the same confining pressure $\sigma_{\mathrm{cd}}$ $: \sigma_{c}$ maintained a constant relation, elastic modulus $E$, peak strength $\sigma_{c}$, crack closure stress $\sigma_{\text {cc }}$, crack initiation stress $\sigma_{\mathrm{ci}}$, expansion stress $\sigma_{\mathrm{cd}}$, and cohesion were reduced. The high confining pressure also made the expansion stress and peak strength more similar
(2) In deviatoric stress cyclic loading and unloading process, the axial elastic modulus in loading and unloading process had the same trend that it increased obviously in first cycle and the trend slowed down in the next stages. Under high confining pressure, at fourth stage, the lateral elastic modulus in loading process dropped down, and the corresponding axial elastic modulus kept increasing, which showed the damage in lateral direction appeared earlier. Poisson's ratio increased as loading stage increased, indicating that inner microcracks expanded with stress level increased

(3) In confining pressure cyclic loading and unloading process, the lateral elastic modulus in unloading process was larger than that in loading process. The lateral elastic modulus in loading process first increased and then decreased with the stage degree increased, while the lateral elastic modulus in unloading process decreased with stage increased

(4) In confining pressure cyclic loading and unloading process, the Biot coefficient decreased in first four stages and then increased in the fifth stage, and the higher the confining pressure, the lower the Biot coefficient value, which indicates that damage had a great impact on the Biot coefficient.

\section{Data Availability}

The data used to support the findings of this study are available from the corresponding author upon request.

\section{Conflicts of Interest}

The authors declare that they have no conflicts of interest.

\section{Acknowledgments}

This work was supported by the National Key Research and Development Program of China (No. 2017YFC1501100), National Natural Science Foundation of China (Nos. 12072102, 51939004), Six Talent Peaks Project in Jiangsu Province, and the Program to Cultivate Middle-aged and Young Science Leaders of Colleges and Universities of Jiangsu Province, China. This work was jointly supported by the Scientific and Technological Innovation Projects for Overseas Scholars in Nanjing (B2004806).

\section{References}

[1] R. Giot, C. Auvray, N. Conil, and R. de la Vaissière, "Multistage water permeability measurements on claystone by steady and transient flow methods," Engineering Geology, vol. 247, pp. 27-37, 2018.

[2] J. Jeanpert, M. Iseppi, P. M. Adler et al., "Fracture controlled permeability of ultramafic basement aquifers. Inferences from the Koniambo massif," Engineering Geology, vol. 256, pp. 6783, 2019.

[3] L. Wang, J. F. Liu, J. L. Pei, H. N. Xu, and Y. Bian, "Mechanical and permeability characteristics of rock under hydro- 
mechanical coupling conditions," Environment and Earth Science, vol. 73, no. 10, pp. 5987-5996, 2015.

[4] W. A. N. G. Huan-ling, X. U. Wei-ya, and Y. A. N. G. Sheng-qi, "Experimental investigation on permeability evolution law during course of deformation and failure of rock specimen," Rock and Soil Mechanics, vol. 27, no. 10, pp. 1703-1708, 2006.

[5] J. Heiland, "Permeability of triaxially compressed sandstone: influence of deformation and strain-rate on permeability," Pure and Applied Geophysics, vol. 160, no. 5-6, pp. 889-908, 2003.

[6] W. Wei, Z. Zheng, R. B. Wang, H. L. Wang, and W. Y. Xu, "Experimental study of permeability properties of granitic gneiss under different stress paths," Chinese Journal of Rock Mechanics and Engineering, vol. 35, no. 2, pp. 260-267, 2016.

[7] P. Zhang, C. Zhao, J. Hou, T. Li, and X. Zhang, "Experimental study on seepage characteristics of deep sandstone under temperature-stress-seepage coupling conditions," Chinese Journal of Rock Mechanics and Engineering, vol. 39, no. 10, pp. 1957-1974, 2020.

[8] J. Zhang, Z. Song, W. Fan, and D. Wang, "Experimental study on mechanical behavior and permeability characteristics of sandstone under stress-seepage coupling," Chinese Journal of Rock Mechanics and Engineering, vol. 38, no. 7, pp. 13641372, 2019.

[9] Y. I. N. Liming, G. U. O. Weijia, and C. H. E. N. Juntao, "Development of true triaxial rock test system of coupled stress-seepage and its application," Chinese Journal of Rock Mechanics and Engineering, vol. 33, no. Supp. 1, pp. 28202826, 2014.

[10] Y. Zhang, W. Xu, H. Zhao, W. Wang, and J. Shao, "Investigation on permeability evolution of sandstone from fractured zone under coupling action of hydro-mechanical-creep," Journal of China University of Petroleum, vol. 38, no. 4, pp. 154161, 2014.

[11] J. Yu, H. Li, and X. Chen, "et alTriaxial experimental study of associated permeability-deformation of sandstone under hydro-mechanical coupling," Chinese Journal of Rock Mechanics and Engineering, vol. 32, no. 6, pp. 1203-1211, 2013.

[12] Y. I. N. Liming and C. H. E. N. Juntao, "Experimental study of influence of seepage pressure on joint stress-seepage coupling characteristics," Rock and Soil Mechanics, vol. 34, no. 9, pp. 2563-2568, 2013.

[13] M. Oda, T. Takemura, and T. Aoki, "Damage growth and permeability change in triaxial compression tests of Inada granite," Mechanics of Materials, vol. 34, no. 6, pp. 313-331, 2002.

[14] O. Schulze, T. Popp, and H. Kern, "Development of damage and permeability in deforming rock salt," Engineering Geology, vol. 61, no. 2-3, pp. 163-180, 2001.

[15] Y. Lu, H. Sun, G. Chen, and H. Zhang, "Evolvement law of rock and water coupling parameters," Engineering Mechanics, vol. 27, no. 2, pp. 19-29, 2010.

[16] W. Sun, Y. Xue, L. Yin, and J. Zhang, "Experimental study on seepage characteristics of large size rock specimens under three-dimensional stress," Geomechanics and Engineering, vol. 18, no. 6, pp. 567-574, 2019.

[17] Z. Liu, J. Shao, and Y. Xu, "Water saturation induced strength degradation of Callovo-Oxfordian claystone," Bifurcation and Degradation of Geomaterials with Engineering Applications, pp. 11-17, 2017.

[18] F. Zhang, D. W. Hu, S. Y. Xie, and J. F. Shao, "Influences of temperature and water content on mechanical property of argillite," European Journal of Environmental and Civil Engineering, vol. 18, no. 2, pp. 173-189, 2013.

[19] M. Bornert, F. Val̃̃ “s, H. Gharbi, and D. Nguyen Minh, "Multiscale full-field strain measurements for micromechanical investigations of the hydromechanical behaviour of clayey rocks," Strain, vol. 46, no. 1, pp. 33-46, 2010.

[20] Z. B. Liu and J. F. Shao, "Moisture effects on damage and failure of Bure claystone under compression," Géotechnique Letters, vol. 6, no. 3, pp. 182-186, 2016.

[21] B. Li, R. Bao, Y. Wang, R. Liu, and C. Zhao, "Permeability evolution of two-dimensional fracture networks during shear under constant normal stiffness boundary conditions," Rock Mechanics and Rock Engineering, vol. 54, no. 3, pp. 120, 2021.

[22] J. Yu, W. Yao, K. Duan, X. Liu, and Y. Zhu, "Experimental study and discrete element method modeling of compression and permeability behaviors of weakly anisotropic sandstones," International Journal of Rock Mechanics and Mining Sciences, vol. 134, p. 104437, 2020.

[23] S. Wang, W. Xu, and W. Wang, "Experimental and numerical investigations on hydro-mechanical properties of saturated fine-grained sandstone," International Journal of Rock Mechanics and Mining Sciences, vol. 127, article 104222, 2020.

[24] W. Wang, X. Chen, Z. Tian, Z. Qizhi, X. Weiya, and R. Huaining, "Experimental study on stress-seepage coupling properties of sandstone under different drainage conditions," Chinese Journal of Rock Mechanics and Engineering, vol. 35, no. s2, pp. 3540-3551, 2016.

[25] D. W. Hu, F. Zhang, J. F. Shao, and B. Gatmiri, "Influences of mineralogy and water content on the mechanical properties of argillite," Rock Mechanics and Rock Engineering, vol. 47, no. 1, pp. 157-166, 2014.

[26] C. D. Su, Z. Q. Xiong, X. X. Zhai, and M. Gu, "Analysis of deformation and strength characteristics of coal samples under the triaxial cyclic loading and unloading stress path," Journal of Mining \& Safety Engineering, vol. 31, no. 3, pp. 456-461, 2014.

[27] J. P. Zuo, H. P. Xie, B. B. Meng, and J. F. Liu, "Experimental research on loading-unloading behavior of coal-rock combination bodies at different stress levels," Rock and Soil Mechanics, vol. 32, no. 5, pp. 1287-1296, 2011.

[28] Y. Wang, W. K. Feng, R. L. Hu, and C. H. Li, "Fracture evolution and energy characteristics during marble failure under triaxial fatigue cyclic and confining pressure unloading (FCCPU) conditions," Rock Mechanics and Rock Engineering, vol. 54, no. 2, pp. 799-818, 2021.

[29] Z. Liu, J. Shao, S. Xie, N. Conil, and J. Talandier, "Mechanical behavior of claystone in lateral decompression test and thermal effect," Rock Mechanics and Rock Engineering, vol. 52, no. 2, pp. 321-334, 2019.

[30] E. D. Eberhardt, Brittle Rock Fracture and Progressive Damage in Uniaxial Compression, [Ph.D. thesis], University of Saskatchewan, Saskatoon, Sask, 1998.

[31] Z.-D. Zhu, Y. Zhang, W.-Y. Xu, F.-D. Xing, and S.-J. Wang, "Experimental studies and microcosmic mechanics analysis on marble rupture under high confining pressure and high hydraulic pressure," Chinese Journal of Rock Mechanics and Engineering, vol. 34, no. 6, pp. 1091-1100, 2015.

[32] C. D. Martin, "Seventeenth Canadian geotechnical colloquium: the effect of cohesion loss and stress path on brittle rock strength," Canadian Geotechnical Journal, vol. 34, no. 5, pp. $698-725,1997$. 
[33] D. Krajcinovic and M. A. G. Silva, "Statistical aspects of the continuous damage theory," International Journal of Solids and Structures, vol. 18, no. 7, pp. 551-562, 1982.

[34] A. Nur and J. Byerlee, "An exact effective stress law for elastic deformation of rock with fluids," Journal of Geophysical Research, vol. 76, no. 26, pp. 6414-6419, 1971.

[35] R. Kherbouche, J. Shao, F. Skoczylas, and J. Henry, "On the poroplastic behavior of porous rocks," European Journal of Mechanics Series Asolids, vol. 14, pp. 577-577, 1995. 